\title{
Article \\ Novel Transcriptome Study and Detection of Metabolic Variations in UV-B-Treated Date Palm (Phoenix dactylifera cv. Khalas)
}

\author{
Mohamed Maher ${ }^{1,2,+}(\mathbb{D})$, Hasan Ahmad ${ }^{1,3,+}$, Elsayed Nishawy ${ }^{1,4}\left(\mathbb{D}\right.$, Yufei Li $^{1}$ and Jie Luo ${ }^{1,5, *}$ \\ 1 National Key Laboratory of Crop Genetic Improvement and National Center of Plant Gene \\ Research (Wuhan), Huazhong Agricultural University, Wuhan 430070, China; \\ mohamed13@webmail.hzau.edu.cn (M.M.); hasanngb@webmail.hzau.edu.cn (H.A.); \\ elnishawy@mail.hzau.edu.cn (E.N.); yf.li@webmail.hzau.edu.cn (Y.L.) \\ 2 Department of Biochemistry, College of Agriculture, Zagazig University, Zagazig 44511, Egypt \\ National Gene Bank, Agricultural Research Center (ARC), Giza 12619, Egypt \\ Desert Research Center, Genetics Resource Department, Egyptian Deserts Gene Bank, Cairo 11735, Egypt \\ 5 Institute of Tropical Agriculture and Forestry of Hainan University, Haikou 570288, China \\ * Correspondence: jie.luo@hainanu.edu.cn \\ $\dagger$ These authors contributed equally to this work.
}

Citation: Maher, M.; Ahmad, H.; Nishawy, E.; Li, Y.; Luo, J. Novel Transcriptome Study and Detection of Metabolic Variations in UV-B-Treated Date Palm (Phoenix dactylifera cv. Khalas). Int. J. Mol. Sci. 2021, 22, 2564. https://doi.org/10.3390/ ijms22052564

Academic Editor: María Serrano

Received: 28 January 2021

Accepted: 17 February 2021

Published: 4 March 2021

Publisher's Note: MDPI stays neutral with regard to jurisdictional claims in published maps and institutional affiliations.

Copyright: (c) 2021 by the authors. Licensee MDPI, Basel, Switzerland. This article is an open access article distributed under the terms and conditions of the Creative Commons Attribution (CC BY) license (https:// creativecommons.org/licenses/by/ $4.0 /)$

\begin{abstract}
Date palm (Phoenix dactylifera) is one of the most widespread fruit crop species and can tolerate drastic environmental conditions that may not be suitable for other fruit species. Excess UV-B stress is one of the greatest concerns for date palm trees and can cause genotoxic effects. Date palm responds to UV-B irradiation through increased DEG expression levels and elaborates upon regulatory metabolic mechanisms that assist the plants in adjusting to this exertion. Sixtyday-old Khalas date palm seedlings (first true-leaf stage) were treated with UV-B (wavelength, $253.7 \mathrm{~nm}$; intensity, $75 \mu \mathrm{W} \mathrm{cm}{ }^{-2}$ for $72 \mathrm{~h}$ ( $16 \mathrm{~h}$ of UV light and $8 \mathrm{~h}$ of darkness). Transcriptome analysis revealed 10,249 and 12,426 genes whose expressions were upregulated and downregulated, respectively, compared to the genes in the control. Furthermore, the differentially expressed genes included transcription factor-encoding genes and chloroplast- and photosystem-related genes. Liquid chromatography-tandem mass spectrometry (LC-MS/MS) was used to detect metabolite variations. Fifty metabolites, including amino acids and flavonoids, showed changes in levels after UV-B excess. Amino acid metabolism was changed by UV-B irradiation, and some amino acids interacted with precursors of different pathways that were used to synthesize secondary metabolites, i.e., flavonoids and phenylpropanoids. The metabolite content response to UV-B irradiation according to hierarchical clustering analysis showed changes in amino acids and flavonoids compared with those of the control. Amino acids might increase the function of scavengers of reactive oxygen species by synthesizing flavonoids that increase in response to UV-B treatment. This study enriches the annotated date palm unigene sequences and enhances the understanding of the mechanisms underlying UV-B stress through genetic manipulation. Moreover, this study provides a sequence resource for genetic, genomic and metabolic studies of date palm.
\end{abstract}

Keywords: date palm; Phoenix dactylifera; transcriptome analysis; amino acids and secondary metabolites

\section{Introduction}

Date palm (Phoenix dactylifera) is one of the most widespread fruit crop species in several arid and semiarid countries, i.e., those in North Africa, the Middle East and Central America [1]. The cultivar Khalas is one of the most common cultivars worldwide, and its fruit is among the best of the soft fruit types [2-4]. Date palm can tolerate drastic environmental conditions that may not be suitable for other fruit species [5]. In full sun or partial shade, date palm trees grow and are tolerant to drought. In any kind of soil, 
even relatively salty soils, they can thrive, but need good drainage. While the date palm is adaptable to various growing conditions, date fruit is produced only in dry and hot climates [6,7]. Date palm growth may be hindered by the violet and yellow ends of the electromagnetic spectrum but may be enhanced by rays at the other end of the spectrum.

Increasing amounts of UV-B radiation have reached the Earth's surface and the surfaces of plants due to stratospheric ozone layer degradation [8]. UV-B radiation is a powerful environmental factor that affects many aspects of the life of a plant, including development, growth, and morphology. [9,10]. Numerous reports have shown that date palm trees, UV-A ( $320 \mathrm{~nm}$ to $400 \mathrm{~nm})$ and UV-B $(290 \mathrm{~nm}$ to $320 \mathrm{~nm})$ are of the greatest concern. Excess UV-B rays can cause genotoxic effects, which are linked to the ability of UV-B to induce direct DNA damage in date palm [11]. UV-B damage involves the direct formation of thymine dimers or other dimers of pyrimidine and double-stranded DNA breaks. [11,12].

UV-B stress has caused plants to improve ways of modifying their metabolism and reconfiguring their internal networks of metabolism. Under UV radiation, plants produce high levels of many amino acids and some of their derivatives, such as Glu, Ala, Lys, Phe and $\gamma$-amino butyrate [13]. This altered activity, occurring after UV-B treatment at the primary-metabolite stage and leading to the synthesis of functional secondary metabolites that can defend against UV-B damage, has improved. $[13,14]$. UV-B is also considered a source of oxidative stress [15-17]. Additionally, UV-B leads to increased glutathione (GSH) and multiple alkaloid content, as well as increased activity of the superoxide dismutase (SOD) and peroxidase (POD) enzymes, which can be due to the generation of reactive oxygen species (ROS) [18].

The date palm response to UV radiation depends on secondary metabolite accumulation $[6,19]$. In addition, the amount of change occurring in the phenylpropanoid pathway determines the harmful effects of date palm caused by UV radiation [13,15]. Furthermore, flavonoids might function as antioxidants during photoprotection [20,21].

Despite the availability of a reference genome [22,23] along with a genetic map of date palm [24], there are limited expression analysis studies on date palm in response to UV-B stress [25-27]. Further physiological and molecular studies are, therefore, needed to explain the mechanisms underlying date palm adaptation to UV radiation.

Date palm has natural ecological survival ability, making the genome of this species valuable as a unique source of genes that may be involved in abiotic (UV radiation) stress. However, few studies have been conducted on the effects of UV stress on date palm. Therefore, the aim of this work was to identify UV stress-response genes to establish a useful database of information about the genome of date palm, as well as that of other crop plant species. The current research is the first study on date palm gene expression profiling in response to solar UV stress using high-throughput sequencing of RNA (RNA-seq).

\section{Results}

2.1. Sequence and De Novo Assembly of the Transcriptome of Khalas Date Palm under UV Stress Conditions

The RNA-seq high-throughput sequencing approach was used to sequence the date palm transcripts expressed in response to UV stress in four libraries: Khalas control 1 (CR1), Khalas control 2 (CR2), Khalas UV treatment 1 (UR1), and Khalas UV treatment 2 (UR2). All of them are biological replicates. These transcriptome sequencing libraries were prepared from the first leaf of 60-day-old P. dactylifera cv. Khalas plants treated with UV-B (wavelength, $253.7 \mathrm{~nm}$; intensity, $75 \mu \mathrm{W} \mathrm{cm}^{-2}$ ) for $72 \mathrm{~h}$. The four libraries were separately sequenced using the Illumina high-throughput second-generation sequencing platform. After removing the low-quality reads and all possible contaminants, 43,537,934, 44,128,934, $43,871,714$ and $44,853,794$ total reads and $41,339,168,41,716,324,41,324,006$ and $42,319,388$ mapped reads were obtained from CR1, CR2, CR3 and CR4, respectively. The proportion of nucleotides with a quality value $>30$ ranged from $93 \%$ to $94 \%$. Furthermore, there was no proportion of unknown nucleotides ( $\mathrm{N}$ percentage) in any of the studied libraries. The raw read numbers ranged from $44,378,972$ to $46,206,808$. The clean reads ranged from 
$43,537,934$ to $44,853,794$, with percentages of $98,96,97$ and $97 \%$ for CR1, CR2, CR3 and CR4, respectively. The GC percentages were between 39 and $42 \%$ in the four libraries, as shown in Table 1.

Table 1. Transcriptome sequencing statistical summary of sequenced and assembled results.

\begin{tabular}{ccccc}
\hline & KhalasCR1 & KhalasCR2 & KhalasUR1 & KhalasUR2 \\
\hline Total Reads & $43,537,934$ & $44,128,934$ & $43,871,714$ & $44,853,794$ \\
Mapped Reads & $41,339,168$ & $41,716,324$ & $41,324,006$ & $42,319,388$ \\
Unmapped Reads & $2,198,766$ & $2,412,610$ & $2,547,708$ & $2,534,406$ \\
Raw Bases Number & $6,656,845,800$ & $6,829,804,800$ & $6,770,265,000$ & $6,931,021,200$ \\
GC\% & $40 \%$ & $39.7 \%$ & $41.6 \%$ & $39.9 \%$ \\
Q30\% & $94.59 \%$ & $93.89 \%$ & $93.05 \%$ & $94.6 \%$ \\
Ns Reads (\%) & 0.15 & 0.17 & 0.26 & 0.27 \\
Raw Reads Number & $44,378,972$ & $45,532,032$ & $45,135,100$ & $46,206,808$ \\
Clean Reads Number & $43,537,934$ & $44,128,934$ & $43,871,714$ & $44,853,794$ \\
Clean Reads Rate (\%) & 98.11 & 96.92 & 97.2 & 97.07 \\
N percentage & 00.00 & 00.00 & 00.00 & 00.00 \\
\hline
\end{tabular}

$\overline{\mathrm{Nt}}$, total number of clean nucleotides; the $\mathrm{GC} \%$ is the proportion of guanidine and cytosine nucleotides among total nucleotides; the $\mathrm{Q} 30 \%$ is the proportion of nucleotides with a quality value $>30$, respectively; the $\mathrm{N} \%$ is the proportion of unknown nucleotides in clean reads.

\subsection{Functional Annotations}

To identify the functions of novel date palm genes, the differentially expressed genes (DEGs) were annotated with a BLASTX search against the NR NCBI protein database content with a cutoff E-value $\geq 10^{-5}$ depending on sequence similarity. In this study, 26,091 unigenes were detected, including $17,003(65.17 \%)$ with uncharacterized proteins or unknown function. Furthermore, out of the total obtained genes, the sequences of 4646 genes were subjected to Gene Ontology $(\mathrm{GO})$ analysis to determine the fundamental functions of the novel genes. A total of 8643 (33.12\%) obtained sequences were submitted to the Clusters of Orthologous Groups/euKaryotic Orthologous Groups (COG/KOG) database, which revealed that the highest number of genes were categorized as "posttranslational modification, protein turnover and chaperones". In addition, 8294 (31.79\%) sequences had matches in the Kyoto Encyclopedia of Genes and Genomes (KEGG) database, 26,021 $(99.73 \%)$ had matches in the Protein families (Pfam) database, and 25,136 (96.34\%) matched to NCBI nonredundant (Nr) protein sequences (Figure 1).

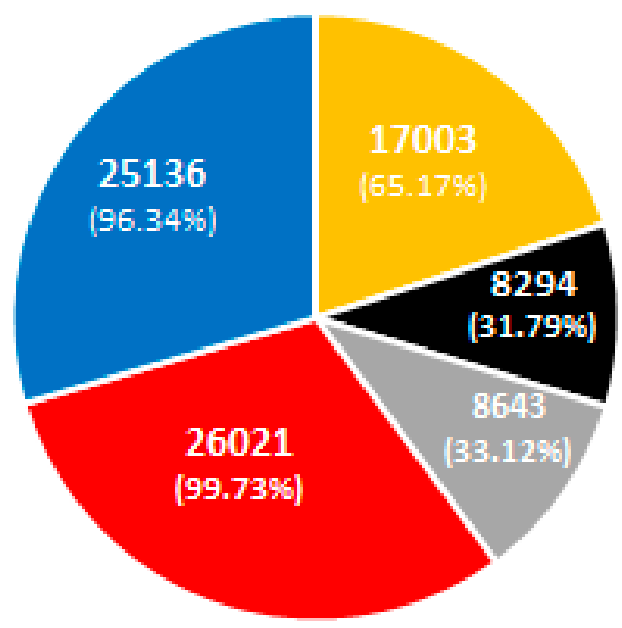

$\| \mathrm{GO}$-KEGG $\|\mathrm{COG} / \mathrm{KOG}\| \mathrm{Pfam} \| \mathrm{Nr}$

Figure 1. Annotated number Values (\%) GO, KEGG, COG/KOG, pfam and NR percentage. 


\subsection{Gene Ontology (GO) Analysis}

The obtained sequences that were subjected to GO were classified into three categories: cellular components, biological processes and molecular functions. The genes in the cellular component category, which is related to cellular compartments and structures affected by UV-B included genes distributed in 15 subcategories. The cellular components most affected by UV-B were cell parts, organelles and membranes. This indicates that the genes responsible for different cellular components and organelles as well as membranes are highly affected by UV-B. Among genes categorized as being associated with biological processes, cellular processes and metabolic processes were the most enriched subcategories. For molecular function, the functions most affected by UV-B treatment were binding and catalytic activity, as shown in Figure 2.

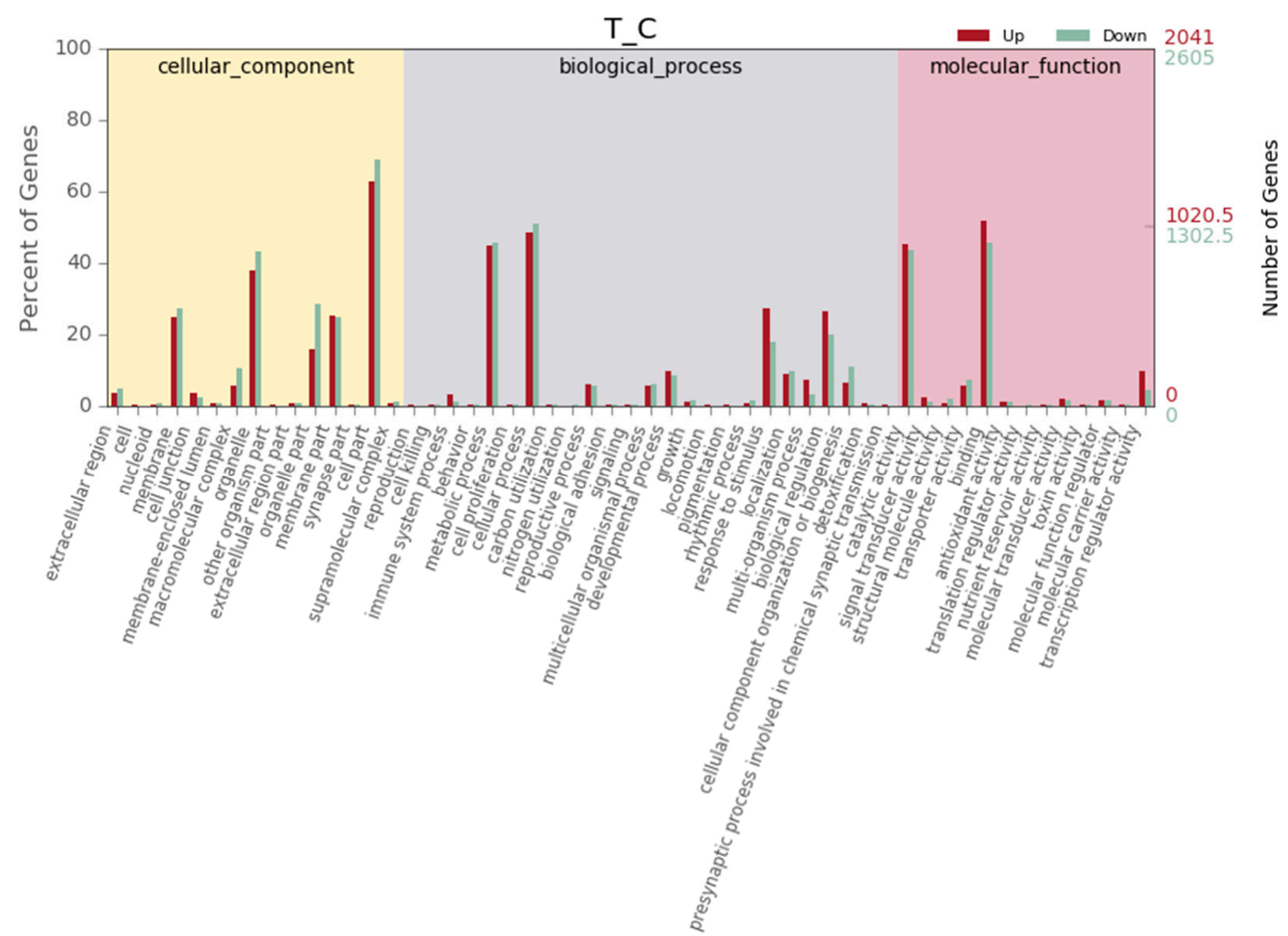

Figure 2. GO functional classification of Date palm unigenes. Gene Ontology (GO) terms are summarized in three main categories of biological process, molecular function and cellular component.

\subsection{Differentially Expressed Genes (DEGs)}

Different expression patterns of 60-day-old date palm seedlings under UV-B stress were profiled to develop a better understanding of the plant response to UV light. After the seedlings were subjected to $72 \mathrm{~h}$ of UV-B treatment, differentially expressed genes, including those whose expressions were up- or downregulated, were compared to those of the control, the results of which are shown in Table 2. Among the four libraries, due to UV-B stress, compared to genes of the control, the expression of 10,249 and 12,426 genes was upregulated and downregulated, respectively. These differentially expressed genes are thus associated with UV-B stress. 
Table 2. Differentially expressed genes (DEGs) in date palm leaf tissues under UV-B stress.

\begin{tabular}{|c|c|c|c|c|c|}
\hline Unigene ID & $\begin{array}{l}\text { Log-Fold } \\
\text { Change }\end{array}$ & Nr.annotation & $\begin{array}{l}\text { Unigene } \\
\text { ID }\end{array}$ & $\begin{array}{l}\text { Log-Fold } \\
\text { Change }\end{array}$ & Nr.annotation \\
\hline \multicolumn{3}{|r|}{ Upregulated } & \multicolumn{3}{|r|}{ Downregulated } \\
\hline g28829 & 8.65 & proteinYLS9-like & g12140 & 7.29 & galactinol-sucrose galactosyltransferase 2 \\
\hline g25277 & 8.94 & germin-like protein $3-8$ & g13825 & 7.36 & flavonol synthase/flavanone 3-hydroxylase \\
\hline g11369 & 8.79 & protein P21-like & g16474 & 7.28 & fatty acyl-CoA reductase 4 \\
\hline g7305 & 7.07 & $\begin{array}{l}\text { protein SENSITIVE TO PROTON } \\
\text { RHIZOTOXICITY 1-like }\end{array}$ & g11969 & 7.62 & caffeoylshikimate esterase-like \\
\hline g23553 & 7.99 & $\begin{array}{l}\text { SNF1-related protein kinase regulatory } \\
\text { subunit beta-1-like isoform X1 }\end{array}$ & g15215 & -6.21 & protein LSD1 isoform $\mathrm{X} 2$ \\
\hline g20545 & 6.12 & pathogenesis-related protein 1-like & g10248 & -5.64 & CASP-like protein RCOM_0864260 \\
\hline g29694 & 6.20 & transcriptional corepressor LEUNIG & g11089 & -5.21 & abscisic acid receptor PYL2 \\
\hline g13273 & 6.40 & auxin-induced protein $\mathrm{X} 10 \mathrm{~A}$ & g18749 & -5.20 & CASP-like protein 6 \\
\hline g11179 & 6.23 & probable glutathione S-transferase & g3051 & -5.75 & WAT1-related protein At1g09380 \\
\hline g23192 & 6.33 & $\begin{array}{l}\text { hypothetical protein [Beta vulgaris } \\
\text { subsp. vulgaris] }\end{array}$ & g17284 & -5.89 & 3-ketoacyl-CoA synthase 6-like \\
\hline g20792 & 6.91 & premnaspirodiene oxygenase-like & g14976 & -5.12 & $\begin{array}{l}\text { histone-lysine N-methyltransferase EZ1-like } \\
\text { isoform X1 }\end{array}$ \\
\hline g8764 & 5.52 & calcium-binding protein CML36 & g17477 & -5.85 & flowering-promoting factor 1 -like protein 3 \\
\hline g16674 & 5.59 & glucosidase 2 subunit beta & g13339 & -5.36 & $\begin{array}{c}\text { short-chain dehydrogenase reductase 3a } \\
\text { isoform X2 }\end{array}$ \\
\hline g11260 & 5.61 & strigolactone esterase D14 & g17022 & -4.28 & delta (8)-fatty-acid desaturase 1-like \\
\hline g27446 & 5.86 & mavicyanin-like & g17881 & -4.26 & $\begin{array}{c}\text { transcription repressor OFP13-like } \\
\text { isoform X2 }\end{array}$ \\
\hline g6909 & 5.85 & calcium-binding protein CML36 & g27128 & -4.95 & probable beta-1,3-galactosyltransferase 6 \\
\hline g9368 & 5.73 & $\mathrm{ABC}$ transporter $\mathrm{B}$ family member 11-like & g15595 & -4.37 & very-long-chain 3-oxoacyl-CoA reductase 1 \\
\hline g5355 & 5.45 & $\begin{array}{l}\text { putative receptor-like protein } \\
\text { kinase At4g00960 }\end{array}$ & g12155 & 4.45 & homeobox protein BEL1 homolog \\
\hline g20793 & 4.10 & premnaspirodiene oxygenase-like & g4508 & -4.02 & protein IQ-DOMAIN 1 \\
\hline g29073 & 4.17 & putative disease resistance protein RGA3 & g10506 & -4.91 & transcription factor RF2b-like \\
\hline g29590 & 4.99 & $\begin{array}{l}\text { cysteine-rich receptor-like protein } \\
\text { kinase } 10 \text {, partial }\end{array}$ & g734 & -4.49 & $\begin{array}{l}\text { glucan endo-1,3-beta-glucosidase 14-like } \\
\text { isoform X1 }\end{array}$ \\
\hline \multirow[t]{2}{*}{ g28226 } & 4.52 & premnaspirodiene oxygenase-like & g967 & -4.58 & $\begin{array}{c}\text { long chain acyl-CoA synthetase } 6 \\
\text { peroxisomal-like }\end{array}$ \\
\hline & & & g10070 & -4.95 & $\begin{array}{l}\text { DNA-damage-repair/toleration } \\
\text { protein DRT100 }\end{array}$ \\
\hline
\end{tabular}

Among these genes, whose expressions were upregulated, three were expressed at levels 8-fold higher than those in untreated plants, including those encoding the protein YLS9-like, germin-like protein 3-8 and the protein P21-like. The proteins encoded by these three genes whose expressions were upregulated act as plant cell defenders that activate the hypersensitive response against stress. These results indicate that genes play a major role in the response of plants to UV-B stress. Furthermore, there were two identified genes that were expressed in leaf tissues and whose expression was more than 7-fold higher in UV-B-treated plants than in the control plants. These two genes encoded the protein sensitive to proton rhizotoxicity 1-like and SNF1-related protein kinase regulatory subunit beta-1-like isoform $\mathrm{X} 1$, which regulated several mechanisms related to specific stress tolerance mechanisms, particularly $\mathrm{H}^{+}$tolerance mechanisms.

Six genes were the third most highly expressed genes, with more than six-fold higher expression in UV-exposed leaf tissue than in control plant leaf tissue. These transcripts were aligned to pathogenesis-related protein 1-like, the transcriptional corepressor LEUNIG, auxin-induced protein $\mathrm{X} 10 \mathrm{~A}$, glutathione S-transferase, and premnaspirodiene oxygenaselike, and there was one uncharacterized protein sequence. Furthermore, seven genes were expressed at levels fivefold-higher than those of the control; these genes have functions strongly related to responses to biotic and abiotic stresses (UV light; Table 2).

However, due to UV-B light, some plant functions were negatively influenced by the relatively low expression values of related genes. These genes included those that encoded galactosyltransferase 2; flavanone 3-hydroxylase; fatty acyl-CoA reductase 4; caffeoyl shikimate esterase-like; the protein LSD1 isoform X2, whose expression was seven-fold lower than that in control plants; the protein LSD1 isoform X2, whose expression was 
six-fold lower than that in the control. In addition, the expressions of eight transcripts were downregulated in the treated plants, the level of which was five-fold lower than that in the control. These sequences were aligned to CASP-like protein, an abscisic acid receptor, WAT1-related protein, 3-ketoacyl-CoA synthase, histone-lysine, flowering-promoting factor 1-like protein 3 and short-chain dehydrogenase reductase 3a isoform X2.

\subsection{KEGG Pathways Related to UV Radiation}

In response to UV-B stress, several pathways related to metabolic process regulation changed, showing many genes whose expression was up- and downregulated. Furthermore, the expression of various amino acid metabolic pathway-related DEGs dramatically increased after date palm was treated with UV-B irradiation. There were more DEGs involved in phenylalanine, tyrosine and tryptophan, as well as arginine and proline metabolism, than DEGs involved in other pathways, as shown in Figure 3. Additionally, there were more DEGs involved in phenylalanine metabolism, which is neatly related to secondary metabolism, than DEGs involved in most other metabolic pathways under UV-B treatment. These results indicated that UV-B irradiation has been shown to activate amino acids and flavonoid metabolism in date palm leaves. In this work, the identified metabolites, including amino acids and secondary metabolites, were performed comprehensive metabolic profiling to investigate the variations of primary and secondary metabolites in date palm leaves under UV-B irradiation. We identified/annotated 50 metabolites in date palm leaves during the course of UV-B irradiation by using an LC/MS-MS. The log2 fold changes in amino acid contents were determined by hierarchical cluster analysis (HCA). The highest levels of amino acids, including phenylalanine, tryptophan, valine, arginine, and tyrosine, were compared with those of the control, the results of which are shown in Figure 4. The results suggested that UV-B radiation might activate the biosynthesis of amino acids in date palm leaves, and these amino acids might be used to synthesize other metabolites that respond to UV-B radiation or might play important roles in protecting plants against UV-B stress. The results also showed that amino acids work as precursors that act as intermediates for secondary metabolite synthesis. Among the secondary metabolite synthesis pathways, shown in Figure 5, phenylpropanoid metabolism and flavonoid biosynthesis, including many metabolites, showed significant changes in response to UV-B irradiation compared to those in the control, as shown in Figure 6.

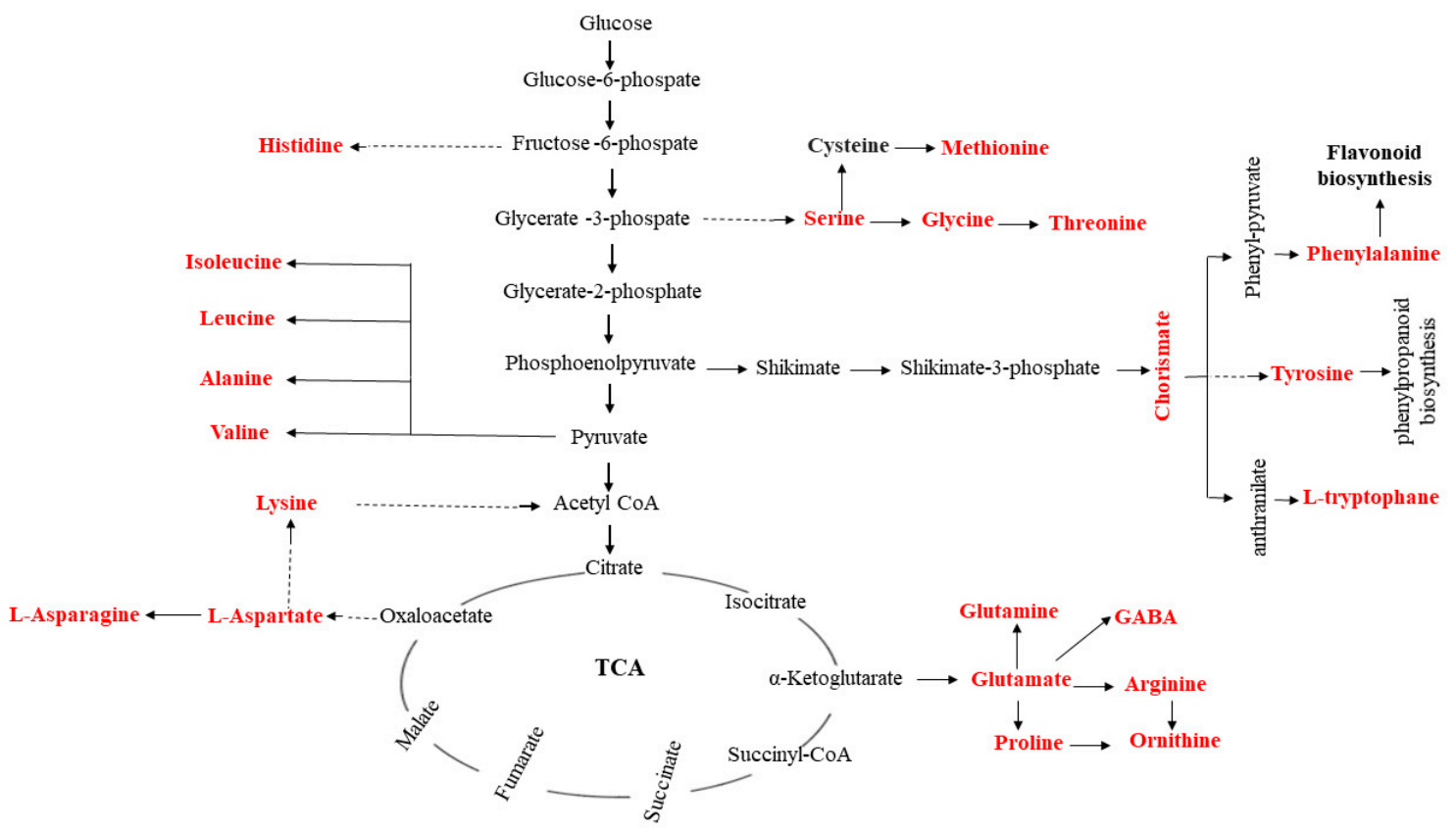

Figure 3. Changes in amino acid levels in the context of amino acid biosynthesis pathways in date palm leaves under UV-B irradiation. Metabolites detected shown in red color, solid lines represent one-step reactions, and dashed lines represent multi-step reactions. 


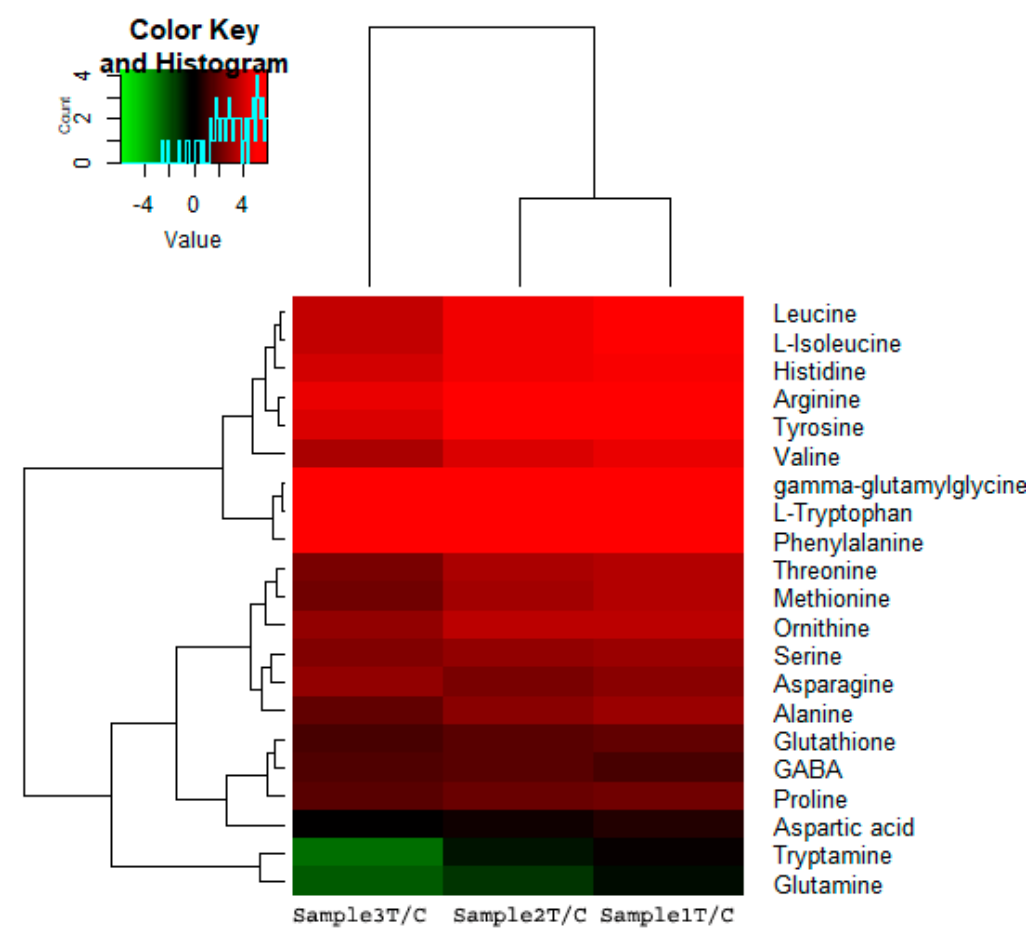

Figure 4. Variations in amino acids levels in date palm leaves under UV-B irradiation compared to the controls. The log2 (fold change) value of three samples treated compared to the control was normalized to complete hierarchical clustering analysis. Red indicates higher amino acid contents in treated samples than in the control, whereas green indicates lower amino contents in treated samples compared to the controls.

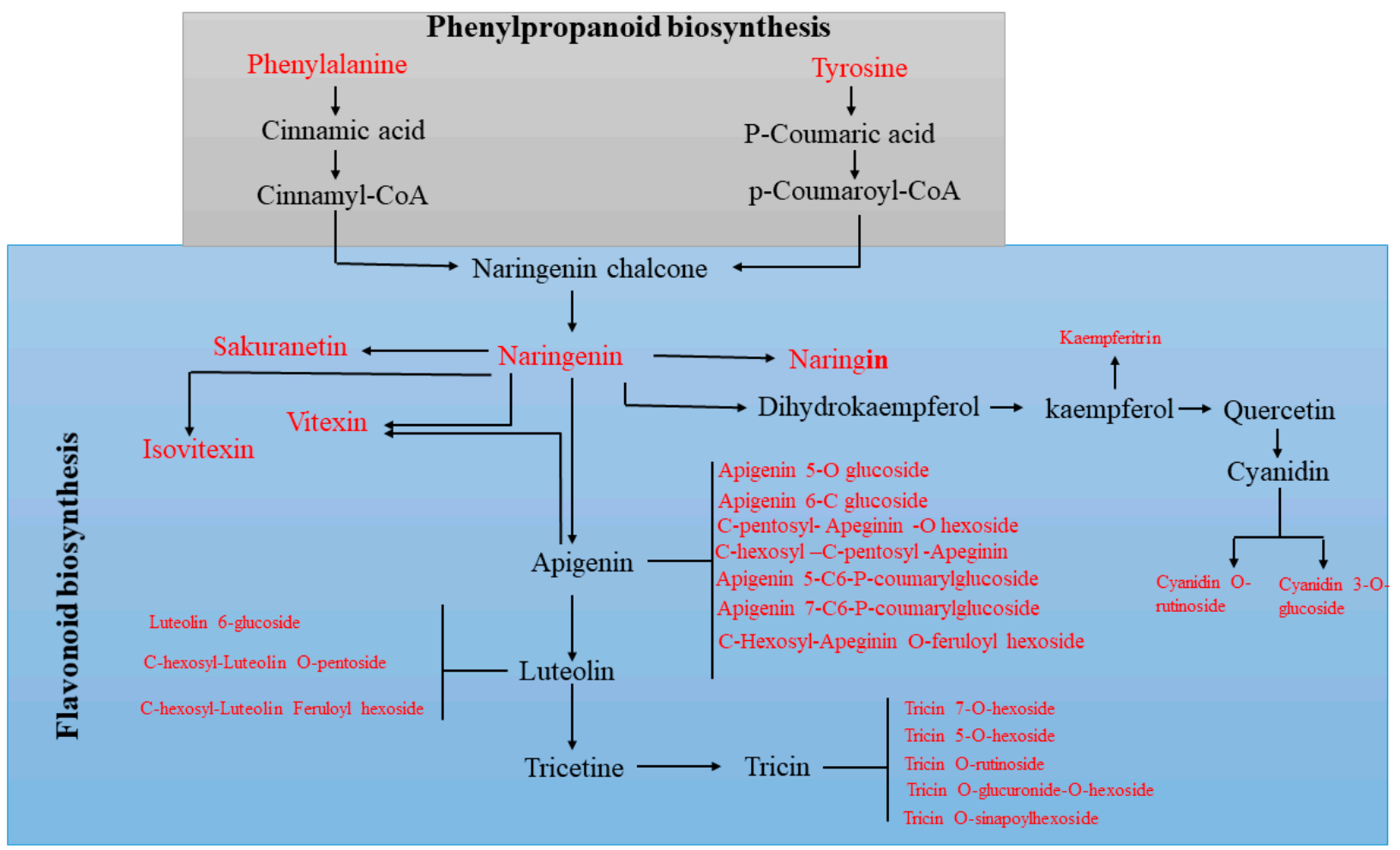

Figure 5. Modulation of phenylpropanoid and flavonoid biosynthesis pathways in date palm leaves under UV-B irradiation. Detected metabolites are indicated with red color. 


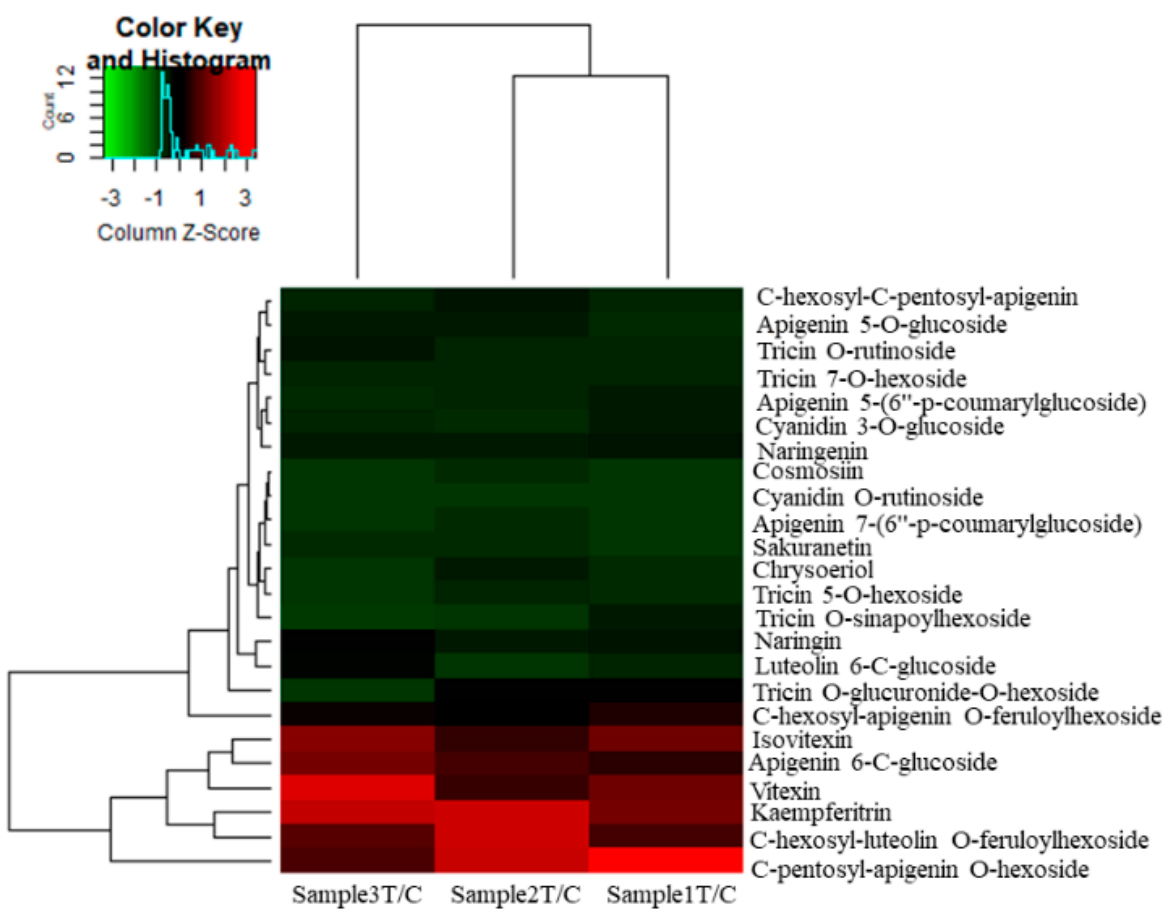

Figure 6. Variations in flavonoid levels in date palm leaves under UV-B irradiation compared to the controls. The fold change value of three samples treated compared to the control was normalized to complete hierarchical clustering analysis. Red indicates higher flavonoids contents in treated samples compared to the control, whereas green indicates lower flavonoids contents in treated samples compared to the controls.

\subsection{Transcription Factors}

According to the NR database, the members of some families of transcription factors showed significant changes in gene expression levels. The most pronounced TF families included the F-box protein (10 and 4 genes, whose expression was upregulated and downregulated, respectively), MYB transcription factor (seven and one genes whose expressions were upregulated and downregulated, respectively), WRKY transcription factor (two and one genes whose expressions were upregulated and downregulated, respectively), chaperone protein (five and one genes whose expressions were upregulated and downregulated, respectively), protein NRT1/PTR (one and four genes whose expressions were upregulated and downregulated, respectively), and $\mathrm{ABC}$ transport (three genes each whose expressions were upregulated and downregulated) families, followed by the GTP binding (one gene each whose expressions were upregulated and downregulated) family. In addition, the expressions of some genes were significantly upregulated, such as those encoding NACs, bHLHs, protein kinases and calmodulin, with total numbers of upregulated genes of three, three, six and three, respectively, as shown in Table 3.

Table 3. Identified transcription factors in date palm leaf tissues under UV-B stress.

\begin{tabular}{|c|c|c|c|c|c|}
\hline Unigene ID & $\begin{array}{l}\text { Log-Fold } \\
\text { Change }\end{array}$ & Nr.annotation & Unigene ID & $\begin{array}{l}\text { Log-Fold } \\
\text { Change }\end{array}$ & Nr.annotation \\
\hline \multicolumn{6}{|c|}{ F-box } \\
\hline g15721 & 3.04 & $\begin{array}{c}\text { F-box/LRR-repeat protein } \\
\text { At4g14103-like }\end{array}$ & g10026 & -1.99 & $\begin{array}{c}\text { F-box/kelch-repeat } \\
\text { protein At5g60570-like }\end{array}$ \\
\hline g16924 & 2.71 & $\begin{array}{c}\text { F-box/LRR-repeat protein } \\
14 \text { isoform X1 }\end{array}$ & g124 & -3.60 & $\begin{array}{c}\text { F-box/kelch-repeat } \\
\text { protein At3g61590-like }\end{array}$ \\
\hline g8642 & 2.21 & $\begin{array}{c}\text { F-box/LRR-repeat MAX2 } \\
\text { homolog A-like }\end{array}$ & g10348 & -1.27 & $\begin{array}{l}\text { EIN3-binding F-box } \\
\text { protein 1-like }\end{array}$ \\
\hline
\end{tabular}


Table 3. Cont.

\begin{tabular}{|c|c|c|c|c|c|}
\hline Unigene ID & $\begin{array}{l}\text { Log-Fold } \\
\text { Change }\end{array}$ & Nr.annotation & Unigene ID & $\begin{array}{l}\text { Log-Fold } \\
\text { Change }\end{array}$ & Nr.annotation \\
\hline g24916 & 1.57 & $\begin{array}{l}\text { F-box protein } \\
\text { At2g26160-like }\end{array}$ & g24 & -5.99 & $\begin{array}{l}\text { F-box protein } \\
\text { At5g49610-like }\end{array}$ \\
\hline g14036 & 1.89 & $\begin{array}{l}\text { F-box/kelch-repeat } \\
\text { protein At5g15710-like }\end{array}$ & & & \\
\hline g12573 & 1.77 & $\begin{array}{c}\text { F-box protein } \\
\text { At4g00755-like isoform X2 }\end{array}$ & & & \\
\hline g2920 & 1.08 & $\begin{array}{l}\text { F-box/kelch-repeat } \\
\text { protein SKIP6-like }\end{array}$ & & & \\
\hline g24233 & 1.79 & $\begin{array}{l}\text { F-box-like/WD } \\
\text { repeat-containing protein } \\
\text { TBL1XR1 }\end{array}$ & & & \\
\hline g2912 & 1.15 & $\begin{array}{c}\text { F-box/kelch-repeat } \\
\text { protein At1g74510-like }\end{array}$ & & & \\
\hline g6822 & 1.04 & $\begin{array}{c}\text { F-boxprotein } \\
\text { At4g18380-like }\end{array}$ & & & \\
\hline \multicolumn{6}{|c|}{ MYB-transcription factor } \\
\hline g10079 & 4.47 & myb-related protein Myb4 & g25632 & -3.89 & $\begin{array}{l}\text { myb-related protein } \\
\text { 306-like }\end{array}$ \\
\hline g7661 & 3.51 & $\begin{array}{l}\text { myb-related protein } \\
\text { 315-like }\end{array}$ & & & \\
\hline g21155 & 2.13 & $\begin{array}{l}\text { myb-related protein } \\
\text { 306-like }\end{array}$ & & & \\
\hline g26123 & 2.22 & $\begin{array}{l}\text { myb-related protein } \\
\text { Zm1-like }\end{array}$ & & & \\
\hline g15549 & 1.83 & $\begin{array}{l}\text { target of Myb protein } \\
\text { 1-like isoform X1 }\end{array}$ & & & \\
\hline g6154 & 2.52 & $\begin{array}{l}\text { transcription } \\
\text { repressor MYB5 }\end{array}$ & & & \\
\hline g9356 & 1.57 & myb-like protein $X$ & & & \\
\hline \multicolumn{6}{|c|}{ NAC transcription factor } \\
\hline g11223 & 4.88 & $\begin{array}{l}\text { NAC domain-containing } \\
\text { protein } 68 \text {-like }\end{array}$ & & & \\
\hline g10695 & 3.92 & $\begin{array}{l}\text { NAC transcription factor } \\
\text { 29-like }\end{array}$ & & & \\
\hline g7306 & 1.07 & $\begin{array}{l}\text { NAC domain-containing } \\
\text { protein } 78\end{array}$ & & & \\
\hline \multicolumn{6}{|c|}{ bHLH transcription factor } \\
\hline g19016 & 3.03 & $\begin{array}{l}\text { transcription factor } \\
\text { bHLH51-like }\end{array}$ & & & \\
\hline g25077 & 2.89 & $\begin{array}{l}\text { transcription factor } \\
\text { bHLH30-like }\end{array}$ & & & \\
\hline g21380 & 2.18 & $\begin{array}{c}\text { transcription factor } \\
\text { bHLH79-like isoform X1 }\end{array}$ & & & \\
\hline \multicolumn{6}{|c|}{ WRKY } \\
\hline g27377 & 3.41 & $\begin{array}{l}\text { WRKY transcription } \\
\text { factor } 9\end{array}$ & g2524 & -1.43 & $\begin{array}{l}\text { WRKY transcription } \\
\text { factor } 44\end{array}$ \\
\hline g10593 & 1.73 & $\begin{array}{l}\text { WRKY transcription factor } \\
\text { 22-like }\end{array}$ & & & \\
\hline
\end{tabular}


Table 3. Cont

\begin{tabular}{|c|c|c|c|c|c|}
\hline Unigene ID & $\begin{array}{l}\text { Log-Fold } \\
\text { Change }\end{array}$ & Nr.annotation & Unigene ID & $\begin{array}{l}\text { Log-Fold } \\
\text { Change }\end{array}$ & Nr.annotation \\
\hline \multicolumn{6}{|c|}{ Protein kinase } \\
\hline g26059 & 3.06 & $\begin{array}{l}\text { protein kinase 2B, } \\
\text { chloroplastic-like }\end{array}$ & & & \\
\hline g22647 & 2.20 & $\begin{array}{l}\text { protein kinase APK1A, } \\
\text { chloroplastic }\end{array}$ & & & \\
\hline g24262 & 2.13 & $\begin{array}{l}\text { shaggy-related protein } \\
\text { kinase alpha isoform X1 }\end{array}$ & & & \\
\hline g27267 & 2.25 & $\begin{array}{l}\text { shaggy-related protein } \\
\text { kinase alpha-like }\end{array}$ & & & \\
\hline g5427 & 1.42 & $\begin{array}{l}\text { Protein kinase APK1A, } \\
\text { chloroplastic isoform X1 }\end{array}$ & & & \\
\hline g29590 & 4.99 & $\begin{array}{l}\text { cysteine-rich receptor-like } \\
\text { protein kinase } 10, \text { partial }\end{array}$ & & & \\
\hline \multicolumn{6}{|c|}{ Chaperone protein } \\
\hline g3048 & 3.18 & $\begin{array}{l}\text { chaperone protein dnaJ 11, } \\
\text { chloroplastic-like }\end{array}$ & g17272 & -3.35 & $\begin{array}{c}\text { BAG family molecular } \\
\text { chaperone regulator 1-like } \\
\text { isoform } \mathrm{X} 1\end{array}$ \\
\hline g17853 & 2.47 & $\begin{array}{l}\text { copper chaperone for } \\
\text { superoxide dismutase, } \\
\text { chloroplastic }\end{array}$ & & & \\
\hline g23747 & 1.52 & $\begin{array}{l}\text { chaperone protein dnaJ } 1 \text {, } \\
\text { mitochondrial isoform } \mathrm{X} 1\end{array}$ & & & \\
\hline g11534 & 1.43 & $\begin{array}{l}\text { chaperone protein dnaJ } 16 \\
\text { isoform X1 }\end{array}$ & & & \\
\hline g14327 & 1.42 & $\begin{array}{l}\text { chaperone protein dnaJ } \\
\text { 16-like }\end{array}$ & & & \\
\hline \multicolumn{6}{|c|}{ Calmodulin } \\
\hline g9795 & 2.10 & calmodulin-like protein 8 & & & \\
\hline g12680 & 1.50 & $\begin{array}{l}\text { calmodulin-binding } \\
\text { transcription activator } \\
\text { 3-like isoform X1 }\end{array}$ & & & \\
\hline g7284 & 1.72 & $\begin{array}{l}\text { calmodulin-binding, } \\
\text { receptor-like cytoplasmic } \\
\text { kinase } 2 \text { isoform X1 }\end{array}$ & & & \\
\hline \multicolumn{6}{|c|}{ protein NRT1/PTR FAMILY } \\
\hline g7578 & 1.19 & $\begin{array}{l}\text { protein NRT1/PTR } \\
\text { FAMILY 8.3-like }\end{array}$ & g23257 & -2.83 & $\begin{array}{l}\text { protein NRT1/PTR } \\
\text { FAMILY 5.6-like }\end{array}$ \\
\hline & & & g25949 & -2.57 & $\begin{array}{l}\text { protein NRT1/PTR } \\
\text { FAMILY 5.1-like }\end{array}$ \\
\hline & & & g13192 & -3.85 & $\begin{array}{l}\text { protein NRT1/PTR } \\
\text { FAMILY 7.3-like } \\
\text { isoform X1 }\end{array}$ \\
\hline & & & g21391 & -3.62 & $\begin{array}{l}\text { protein NRT1/PTR } \\
\text { FAMILY 6.3-like }\end{array}$ \\
\hline
\end{tabular}


Table 3. Cont.

\begin{tabular}{|c|c|c|c|c|c|}
\hline Unigene ID & $\begin{array}{l}\text { Log-Fold } \\
\text { Change }\end{array}$ & Nr.annotation & Unigene ID & $\begin{array}{l}\text { Log-Fold } \\
\text { Change }\end{array}$ & Nr.annotation \\
\hline \multicolumn{6}{|c|}{$\mathrm{ABC}$ transporter } \\
\hline g9368 & 5.73 & $\begin{array}{l}\text { ABC transporter B family } \\
\text { member 11-like }\end{array}$ & g26516 & -3.49 & $\begin{array}{c}\text { ABC transporter B family } \\
\text { member 2-like }\end{array}$ \\
\hline g22460 & 2.52 & $\begin{array}{l}\text { ABC transporter B family } \\
\text { member 21-like }\end{array}$ & g20679 & -3.21 & $\begin{array}{l}\mathrm{ABC} \text { transporter } \mathrm{F} \text { family } \\
\text { member 4-like isoform } \mathrm{X} 1\end{array}$ \\
\hline g9658 & 1.57 & $\begin{array}{c}\text { ABC transporter A family } \\
\text { member } 1\end{array}$ & g15724 & -4.39 & $\begin{array}{c}\text { ABC transporter B family } \\
\text { member 2-like }\end{array}$ \\
\hline \multicolumn{6}{|c|}{ GTP-binding protein } \\
\hline g14812 & 1.17 & $\begin{array}{l}\text { GTP-binding } \\
\text { protein YPTM2 }\end{array}$ & g27583 & -1.56 & $\begin{array}{l}\text { GTP-binding protein } \\
\text { OBGC, chloroplastic } \\
\text { isoform X1 }\end{array}$ \\
\hline
\end{tabular}

\subsection{Chloroplast-Related Genes as Affected by UV Stress}

Plants utilize energy from sunlight to perform photosynthesis in chloroplasts. To evaluate the UV-B stress effects on date palm chloroplast-related genes, differences in genes whose expression was up- or downregulated, and that differed from those of the control, were recorded. The chloroplast-related genes whose expression was most upregulated were those encoding zeaxanthin epoxidase, chaperone protein dnaJ-11 and protein kinase; their expression level was three times higher than that of the control. The expression of 12 genes was 2-fold higher than that of the control, as shown in Table 4. The obtained results showed that the genes whose expression was upregulated were mostly involved in increasing photosynthetic efficiency and in the photosystem II complex in addition to balancing redox reactions in chloroplasts and the response to changing light conditions. On the other hand, the detected genes whose expression was downregulated were involved in functions such as magnesium chelatase catalysis, contributions to the control of energy distribution between the two photosystems (PSI and PSII) and the reassimilation of ammonia generated by photorespiration.

Table 4. Chloroplast genes affected by UV-B stress.

\begin{tabular}{|c|c|c|c|c|c|}
\hline Unigene ID & $\begin{array}{l}\text { Log-Fold } \\
\text { Change }\end{array}$ & Nr.annotation & Unigene ID & $\begin{array}{l}\text { Log-Fold } \\
\text { Change }\end{array}$ & Nr.annotation \\
\hline g20372 & 4.00 & $\begin{array}{l}\text { Zeaxanthin, epoxidase, } \\
\text { chloroplastic-like }\end{array}$ & g21231 & -6.36 & $\begin{array}{l}\text { Thioredoxin M-type, } \\
\text { chloroplastic-like }\end{array}$ \\
\hline g3048 & 3.18 & $\begin{array}{l}\text { chaperone protein dnaJ } 11, \\
\text { chloroplastic-like }\end{array}$ & g26467 & -6.71 & $\begin{array}{c}\text { early light-induced } \\
\text { protein } 1, \\
\text { chloroplastic-like }\end{array}$ \\
\hline g26059 & 3.06 & $\begin{array}{l}\text { protein kinase } 2 \mathrm{~B}, \\
\text { chloroplastic-like }\end{array}$ & g17433 & -6.32 & $\begin{array}{c}\text { magnesium-chelatase } \\
\text { subunit ChlH, } \\
\text { chloroplastic }\end{array}$ \\
\hline g17853 & 2.47 & $\begin{array}{l}\text { copper chaperone for } \\
\text { superoxide dismutase, } \\
\text { chloroplastic }\end{array}$ & g14073 & -5.01 & $\begin{array}{c}\text { protein CURVATURE } \\
\text { THYLAKOID 1B, } \\
\text { chloroplastic }\end{array}$ \\
\hline g22647 & 2.20 & $\begin{array}{l}\text { protein kinase APK1A, } \\
\text { chloroplastic }\end{array}$ & g12540 & -5.32 & $\begin{array}{c}\text { anthranilate synthase beta } \\
\text { subunit } 2, \\
\text { chloroplastic-like } \\
\text { isoform } \mathrm{X} 1\end{array}$ \\
\hline g11261 & 2.52 & $\begin{array}{l}\text { cyanidin 3-O-rutinoside 5- } \\
\text { O-glucosyltransferase-like }\end{array}$ & g4666 & -5.97 & $\begin{array}{l}\text { photosystem II } 22 \mathrm{kDa} \\
\text { protein, chloroplastic }\end{array}$ \\
\hline
\end{tabular}


Table 4. Cont

\begin{tabular}{|c|c|c|c|c|c|}
\hline Unigene ID & $\begin{array}{l}\text { Log-Fold } \\
\text { Change }\end{array}$ & Nr.annotation & Unigene ID & $\begin{array}{l}\text { Log-Fold } \\
\text { Change }\end{array}$ & Nr.annotation \\
\hline g2107 & 2.02 & $\begin{array}{l}\text { alpha-amylase 3, } \\
\text { chloroplastic isoform X1 }\end{array}$ & g6369 & -4.06 & $\begin{array}{l}\text { early light-induced } \\
\text { protein 1, } \\
\text { chloroplastic-like }\end{array}$ \\
\hline g8568 & 2.401 & $\begin{array}{c}\text { dihydropyrimidine } \\
\text { dehydrogenase [NADP } \\
(+) \text { ]-like }\end{array}$ & g15019 & -4.18 & $\begin{array}{l}\text { photosystemII10-kDa- } \\
\text { polypeptide, } \\
\text { chloroplastic-like }\end{array}$ \\
\hline g20708 & 2.00 & $\begin{array}{c}\text { probable L-ascorbate } \\
\text { peroxidase } 6 \text {, chloroplastic }\end{array}$ & g18469 & -4.14 & $\begin{array}{l}\text { Phosphoglycolate- } \\
\text { phosphatase1B, } \\
\text { chloroplastic-like }\end{array}$ \\
\hline g23545 & 2.69 & $\begin{array}{c}\text { peroxisomal } \\
\text { (S)-2-hydroxy-acid oxidase } \\
\text { GLO1-like, partial }\end{array}$ & g24151 & -4.45 & $\begin{array}{c}\text { Glutaminesynthetase-leaf, } \\
\text { isozyme, } \\
\text { chloroplastic, partial }\end{array}$ \\
\hline g27808 & 2.57 & $\begin{array}{l}\text { leucine-tRNA ligase, } \\
\text { cytoplasmic }\end{array}$ & g13326 & -3.24 & $\begin{array}{l}\text { photosystem I reaction } \\
\text { center subunit V, } \\
\text { chloroplastic-like }\end{array}$ \\
\hline g24000 & 2.74 & $\begin{array}{l}\text { short-chain, type } \\
\text { dehydrogenase/reductase-like }\end{array}$ & g2387 & -3.04 & $\begin{array}{l}\text { phytoene synthase 2, } \\
\text { chloroplastic-like }\end{array}$ \\
\hline g4958 & 2.02 & $\begin{array}{l}\text { protein DJ-1 homolog } \\
\text { B-like }\end{array}$ & g12907 & -3.22 & $\begin{array}{l}\text { CBS domain-containing } \\
\text { protein CBSX1, } \\
\text { chloroplastic-like } \\
\text { isoform X1 }\end{array}$ \\
\hline g23419 & 2.23 & $\begin{array}{l}\text { sufE-like protein 2, } \\
\text { chloroplastic }\end{array}$ & g1234 & -3.69 & $\begin{array}{l}\text { psbP-like protein 2, } \\
\text { chloroplastic isoform } \mathrm{X} 1\end{array}$ \\
\hline g1185 & 2.72 & pumilio homolog 4-like & g24998 & -3.86 & $\begin{array}{l}\text { beta-amylase } 1 \text {, } \\
\text { chloroplastic }\end{array}$ \\
\hline g5427 & 1.42 & $\begin{array}{l}\text { protein kinase APK1A, } \\
\text { chloroplastic isoform X1 }\end{array}$ & g8024 & -3.28 & $\begin{array}{l}\text { serine/threonine-protein } \\
\text { kinase STN8, chloroplastic }\end{array}$ \\
\hline g26814 & 1.2 & $\begin{array}{l}\text { glyoxylate/succinic } \\
\text { semialdehyde reductase } 2, \\
\text { chloroplastic-like, partial }\end{array}$ & g11142 & -3.88 & $\begin{array}{l}\text { protein CHUP1, } \\
\text { chloroplastic-like }\end{array}$ \\
\hline g18099 & 1.01709 & $\begin{array}{l}\text { phospholipase A I } \\
\text { isoform X1 }\end{array}$ & g13505 & -3.17 & $\begin{array}{l}\text { elongation factor G-2, } \\
\text { chloroplastic isoform X1 }\end{array}$ \\
\hline g18893 & 1.75339 & $\begin{array}{l}\text { cytochrome c oxidase } \\
\text { subunit 6b-1-like }\end{array}$ & g7192 & -3.36 & $\begin{array}{l}\text { linoleate 13S-lipoxygenase } \\
\text { 2-1, chloroplastic-like }\end{array}$ \\
\hline g16944 & 1.48651 & $\begin{array}{c}\text { Bifunctional, } \\
\text { aspartokinase/homoserine- } \\
\text { dehydrogenase 1, } \\
\text { chloroplastic-like } \\
\text { isoform X2 }\end{array}$ & g28350 & -3.49 & $\begin{array}{l}\text { Translationfactor-GUF1- } \\
\text { homolog, } \\
\text { chloroplastic-like, partial }\end{array}$ \\
\hline g2507 & 1.92168 & $\begin{array}{l}\text { fructose-bisphosphate } \\
\text { aldolase 1, } \\
\text { chloroplastic-like }\end{array}$ & g24478 & -3.23 & $\begin{array}{l}\text { protein TIC 62, } \\
\text { chloroplastic }\end{array}$ \\
\hline g571 & 1.57951 & $\begin{array}{l}\text { stress enhanced protein } 2, \\
\text { chloroplastic }\end{array}$ & g7433 & -3.15 & $\begin{array}{c}\text { oxygen-evolving enhancer } \\
\text { protein } 1, \\
\text { chloroplastic-like }\end{array}$ \\
\hline g22715 & 1.06424 & $\begin{array}{c}\text { probable 6- } \\
\text { phosphogluconolactonase } \\
\text { 4, chloroplastic }\end{array}$ & g19570 & -3.99 & $\begin{array}{c}\text { tuliposide A-converting } \\
\text { enzyme 2, } \\
\text { chloroplastic-like }\end{array}$ \\
\hline g19022 & 1.09656 & $\begin{array}{l}\text { UPF0051 protein in atpA } \\
\text { 3'region-like }\end{array}$ & g16877 & -3.50 & $\begin{array}{c}\text { carbonic anhydrase } 2 \\
\text { isoform } X 1\end{array}$ \\
\hline
\end{tabular}


Table 4. Cont.

\begin{tabular}{|c|c|c|c|c|c|}
\hline Unigene ID & $\begin{array}{l}\text { Log-Fold } \\
\text { Change }\end{array}$ & Nr.annotation & Unigene ID & $\begin{array}{l}\text { Log-Fold } \\
\text { Change }\end{array}$ & Nr.annotation \\
\hline g17153 & 1.06724 & $\begin{array}{l}\text { oleoyl-acyl carrier } \\
\text { protein thioesterase, } \\
\text { chloroplastic-like }\end{array}$ & g8464 & -3.68 & $\begin{array}{l}\text { pheophytinase, } \\
\text { chloroplastic-like }\end{array}$ \\
\hline g3464 & 1.12812 & kinesin-like protein KIF9 & g21644 & -3.45 & $\begin{array}{c}\text { methionine } \\
\text { aminopeptidase 1B, } \\
\text { chloroplastic-like }\end{array}$ \\
\hline g26671 & 1.15177 & $\begin{array}{l}\text { zinc finger protein } \\
\text { MAGPIE-like }\end{array}$ & & & \\
\hline g3448 & 1.38143 & $\begin{array}{c}\text { protein BPS1, } \\
\text { chloroplastic-like }\end{array}$ & & & \\
\hline g1238 & 1.32983 & $\begin{array}{l}\text { protein gar2 [Elaeis } \\
\text { guineensis] }\end{array}$ & & & \\
\hline
\end{tabular}

\subsection{Photosynthesis}

Photosynthesis is the mechanism in which energy from the sun is transformed into chemical energy in sugars. Furthermore, photosystems play a key role in light reactions through large complexes of proteins and pigments (light-absorbing molecules) that react to and harvest light energy. In the current study, great variations occurred in photosystem reactions (PSI and PSII) due to UV-B exposure. Among all genes related to photosystem mechanisms, there were 6 and 7 genes in PSI and PSII, respectively, whose expression changed compared to that in the control. These genes were involved in the PsbO, PsbP, PsbQ, PsbR, PsbS, PSB27-H1 and Psb28 elements in PSII. In addition, another six elements involved genes whose expression was downregulated, viz., PsaD, PsaK, PsaG, PsaL, PsaN and PsaO, in PSI. Photosynthetic electron transport (PET) converts free and abundant sunlight energy into reducing power and chemical energy by transferring electrons in PSI and PSII in chloroplasts. PET is a process that occurs at four different sites: plastocyanin (PC), ferredoxin (FD), ferredoxin NADP(H) oxidoreductase (FNR) and cytochrome c6 (Cyt-c6). Among these four sites, three included two genes whose expressions were downregulated (PC and FD) and one gene whose expression was upregulated (FNR). FNR has a main role in catalyzing the final step of PET, providing $\mathrm{NADPH}$ for $\mathrm{CO}_{2}$ assimilation and another reductive metabolism. However, Cyt-c6 genes did not show a significant effect due to UV-B stress compared that in the control plants, as shown in Figure 7.

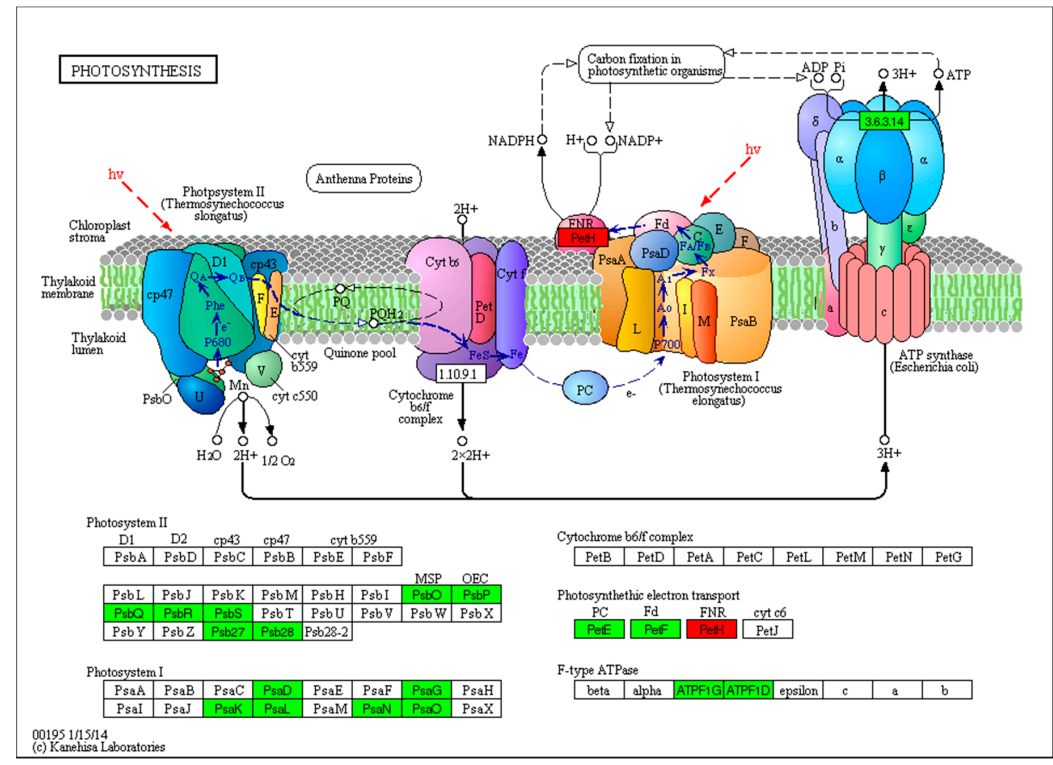

Figure 7. Photosynthesis related genes as affected by UV-B stress. 


\subsection{Oxidative Phosphorylation-Related Genes}

Oxidative phosphorylation is the mechanism by which energy is harnessed to synthesize ATP via a sequence of protein complexes embedded in the inner membrane of mitochondria. In this study, the expression of genes related to oxidative phosphorylation was significantly affected by UV stress; an intramitochondrial signaling pathway that regulates cytochrome oxidase (COX) was also affected. COX also contributes to energy storage in the form of an electrochemical gradient used for the synthesis of ATP via the oxidative phosphorylation system. In addition, the cytochrome $\mathrm{C}$ reductase $\mathrm{fbcH}$ gene product, which is synthesized as a polyprotein precursor for cytochromes $\mathrm{b}$ and $\mathrm{c} 1$, showed a pronounced effect, in terms of its gene expression (Figure 8).

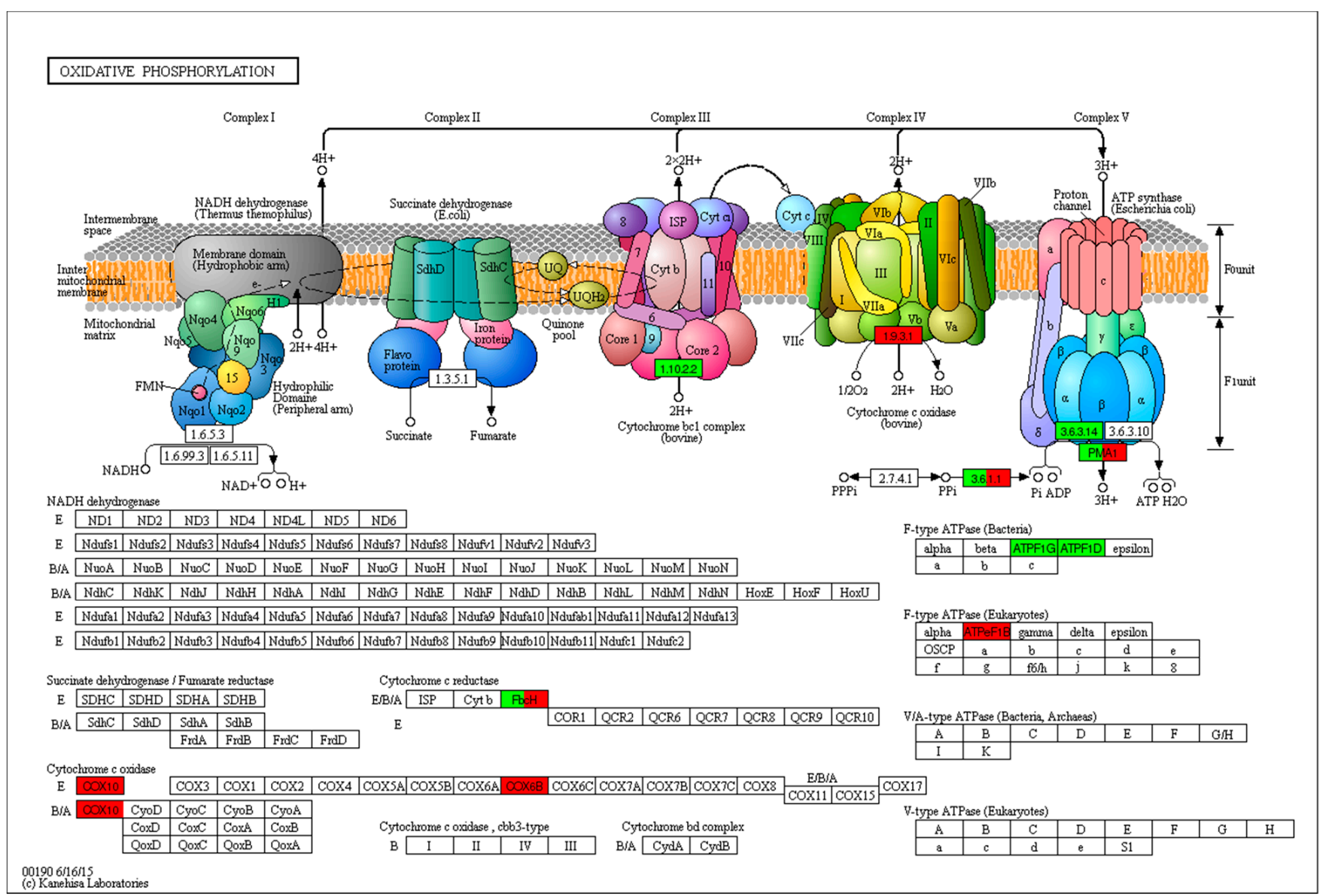

Figure 8. Oxidative phosphorylation-related genes as affected by UV-B stress.

\subsection{Quantitative Real-Time PCR ( $q R T-P C R$ ) Validation of DEGs from RNA-seq}

A validation experiment was conducted using qRT-PCR to confirm the accuracy of the Illumina high-throughput sequencing data. Ten unigenes are chosen at random for quantitative RT-PCR assays: LOC103699391, LOC103695855, LOC103709833, LOC103711915, LOC103715616, LOC103707665, LOC103715998, LOC103719605, LOC103702656 and LOC103716074. The qRT-PCR results showed that the expressions of all of the tested genes were upregulated after treatment with UV-B irradiation, which was compliant with RNA-seq data (Figure 9). Thus, the RNA-seq results were accurate for the identification and measurement of the expression of DEGs involved in different processes in date palm leaves in response to UV-B radiation. 


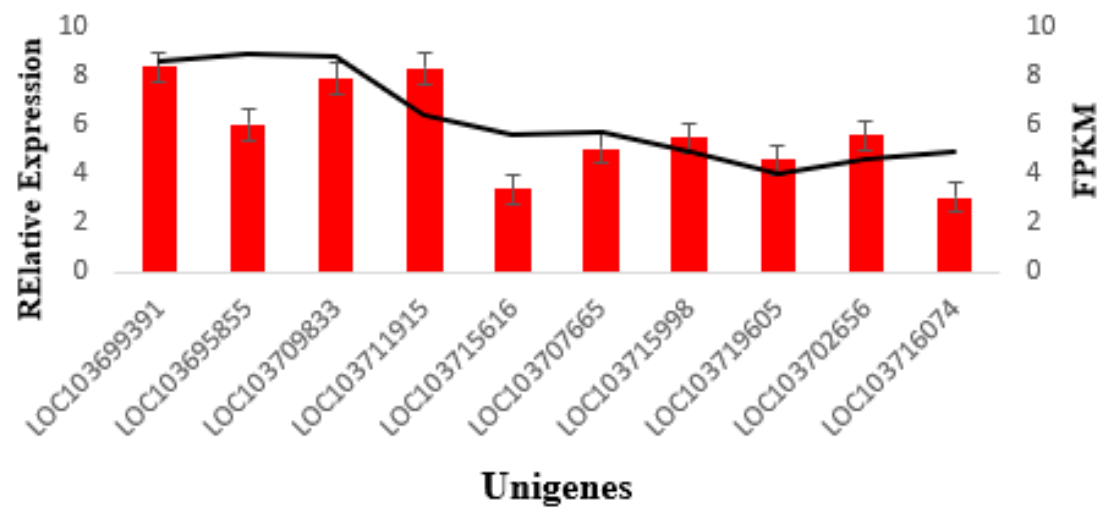

$\log 2$, Fold change by RT-qPCR $\log 2$, Fold-change by RNA-SEQ

Figure 9. Quantitative real-time PCR analysis and fragments per kilo base million mapped read (FPKM) of 10 randomly chosen different expression genes DEGs, expression levels determined by qRT-PCR. Black line presented $\log _{2}$ FPKM of RNA-seq data and red columns presented $\log _{2}$ the fold change of qRT-PCR.

\section{Materials and Methods}

\subsection{Plant Materials}

Sixty-day-old Phoenix dactylifera cv. Khalas plants (first true-leaf stage) were collected by Egyptian Desert Research Center staff from green valley, Al-Kharga with latitude $25^{\circ} 27^{\prime} 16.3476^{\prime \prime} \mathrm{N} 30^{\circ} 33^{\prime} 12.1608^{\prime \prime} \mathrm{E}$ and were treated with UV-B (wavelength, $253.7 \mathrm{~nm}$; intensity, $75 \mu \mathrm{W} \mathrm{cm} \mathrm{cm}^{-2}$ ). The UV-B full lamp description is as follow; a UV-B chamber (Philips, Netherlands, TL8W/302 nm narrowband UVB tube; $12.8 \mu \mathrm{W} \mathrm{cm}{ }^{-2}$; measured using a UV radiometer with the UV-295 detector from photoelectric instrument factory of Beijing normal university) was used in this experiment. There was no filter between the lamp and the treated plants [28]. The seedlings were subjected to UV-B stress for $72 \mathrm{~h}$ (16 h of UV light and $8 \mathrm{~h}$ of darkness). After the treatment, no visible symptoms appeared during the radiation treatment. Samples from the first true leaves were collected from the control as well as UV-B-treated seedlings and directly frozen in liquid nitrogen for RNA extraction.

\subsection{RNA Extraction}

Total RNA was extracted from collected samples by using the TRIzol method (Life Technologies, Carlsbad, CA, USA) according to the manufacturer's protocol. The RNA sample purity was determined by using a Nanophotometer ${ }^{\circledR}$ spectrophotometer (IMPLEN, Westlake Village, CA, USA). To detect the integrity and concentration of RNA samples, an Agilent 2100 RNA Nanodrop 6000 was used (Agilent Technologies, Santa Clara, CA, USA).

\subsection{CDNA Library Preparation for Transcriptome Analysis}

The total amount of RNA for second-generation sequencing was $3 \mu \mathrm{g}$, which was used as input material for the preparation of the library. Sequencing libraries were generated using a NEBNext ${ }^{\circledR}$ Ultra $^{\text {TM }}$ RNA Library Prep Kit for Illumina ${ }^{\circledR}$ (NEB, Ipswich, MA, USA), following the manufacturer's protocol, to assign sequences to each sample, index codes were added. Briefly, purified mRNA was attached to magnetic beads using Poly-T. oligo. After the libraries were constructed, PCR products were purified, and library quality was assessed on the Agilent Bioanalyzer 2100 system.

\subsection{Data Analysis Quality Control}

The quality of the raw data (raw reads) in fastq format was processed through in-house Perl scripts. After we removed low-quality sequences and sequences contaminated with adapters, all subsequent analyses were based on clean reads. The raw reads sequenced from the Illumina platform were processed to obtain high-quality sequences (clean reads). The 
Q30 value, the GC content and the clean data sequence duplication level were determined simultaneously. All downstream analyses were based on clean, high-quality data.

\subsection{Transcriptome Based Assembly}

TPM, FPKM, RPKM and fold change (FC) values were recorded for each replicate of each library separately. The acquired sequence was aligned, and comparable sequence data were obtained from all libraries [29]. Trinity was used for further analysis [29], with min kmer_cov set to 2 by default and with all other parameters set to the default.

\subsection{Gene Annotation and Functional Analysis}

To conduct a functional gene annotation, different source databases were used, including the NCBI, Pfam, KOG/COG and GO databases. NCBI nonredundant protein sequences (Nr) (https://www.ncbi.nlm.nih.gov/ (accessed on 3 February 2021)) with an e-value cutoff of 1E-5, Nt sequences with an e-value cutoff of 1E-5, Pfam (Protein families) (https://pfam.sanger.ac.uk/ (accessed on 3 February 2021)) sequences with an e-value of 1E-2 and KOG/COG (Clusters of Orthologous Groups of proteins) sequences with an e-value of 1E-3 were used. With respect to GO (Gene Ontology) annotations (http:/ / geneontology.org/ (accessed on 3 February 2021)), there are three total ontology categories: Those that identify gene-related molecular functions, cellular components, and biological processes [30]. Our transcriptome was constructed and analyzed by Annoroad Genome Company methods (www.genome.cn (accessed on 3 February 2021)), and all the reference data were downloaded and analyzed in the period between 23 January 2019 to 23 April 2019. The methods were as follows: Alignment of the reference genomes, and the annotation file was downloaded from ENSEMBL database (http:/ / www.ensembl.org/index.html (accessed on 3 February 2021)). Bowtie2 v2.2.3 was used for building the genome index, clean data and aligned to the reference genome using HISAT2 v2.1.0. HISAT2 is the successor to TopHat2, which uses a modified BWT algorithm to convert reference genomes to the index for faster speed and fewer resources. For Function Enrichment Analysis, the GO (Gene Ontology, http: / / geneontology.org/ (accessed on 3 February 2021)) enrichment of DEGs was implemented by the hypergeometric test, in which the p-value is calculated and adjusted as a q-value, and the data background comprises genes in the whole genome. GO terms with q. GO enrichment was introduced for the differentially expressed genes (DEGs) by the hypergeometric distribution method [31]. GO enrichment was considered significant when the threshold $\mathrm{q}<0.05$ was met. Significant GO functional enrichment analysis can determine the main biological functions associated with differentially expressed genes.

The KEGG (Kyoto Encyclopedia of Genes and Genomes) database [32] is a resource for genome deciphering (https:/ / www.genome.jp/kegg/ (accessed on 3 February 2021)). Significant enrichment analysis of each pathway in the KEGG database was implemented by the hypergeometric test method.

\subsection{Quantification of Levels of Gene Expression and Study of Differential Expression}

For each sample plant, the gene expression levels were calculated using RSEM 30. Clean data were mapped back to the assembled transcriptome. Read counts were obtained from the mapping results for each gene in all samples counted by HTSeq v0.6.0 on the basis of FPKM (fragments per kilobase million mapped reads). The DEGseq2 R package reported in [33] was used for determining the differential expression among the digital gene expression data using a model based on a negative binomial distribution. To identify genes whose expression significantly differed, FDR $\leq 0.05$ and a $(\mid \log 2($ fold change $(F C)) \mid)$ $\geq 1$ were set as the thresholds for significance (DEGs) [33].

\subsection{Quantitative and Real Time-PCR ( $q R T-P C R)$ Validation}

To check the precision of the Illumina sequencing results, the different expression levels of the DEGs were confirmed via qRT-PCR using 10 random unigenes. Total RNA 
was extracted from collected samples with the TRIzol method (Life Technologies, Carlsbad, CA, USA), reverse transcribed (Takara, http:/ / ww.takara-bio.com/ (accessed on 3 February 2021)), and subjected to PCR in a BioRad CFX96 Real-Time System according to the manufacturers' instructions. RT-qPCR was carried out using the technique described in [34]. The specific primers used for the ten genes were designed using Primer 5 software (http:/ / www.ncbi.nlm.nih.gov/tools / primer-blast/ primer3 (accessed on 3 February 2021)). In triplicate, all the reaction solutions were prepared and relative expression was calculated using the $2^{\wedge}(-\mathrm{Ct})$ method, with the expression normalized against the internal reference gene (Tubulin) [35]. Sequences of the primers used and the identities of the BLAST hits are provided in Table 5.

Table 5. RT-qPCR primers used for validation experiments.

\begin{tabular}{clll}
\hline Unigene Name & Direction & \multicolumn{1}{c}{ Sequence $\mathbf{( 5}^{\prime}$-> $\mathbf{3}^{\prime}$ ) } & Length \\
\hline LOC103699391 & Forward & GTTCCAGCAGATCTCCACCT & 20 \\
\hline & Reverse & CCGGCAATTCCACTGTTTCA & 20 \\
\hline LOC103695855 & Forward & TTTCGAAAGCAGGCAACACA & 20 \\
\hline LOC103709833 & Reverse & TCGACTCGGTTCATGGAGAG & 20 \\
\hline LOC103711915 & Forward & TTCAACGACATCTCCCTCGT & 20 \\
\hline & Reverse & ATATCCATGCTGCAGTCCGA & 20 \\
\hline LOC103715616 & Forward & ATGACAGGGCTGGTGAAGAA & 20 \\
\hline & Reverse & TGAGCAGGTCCTCAAACAGT & 20 \\
\hline LOC103707665 & Forward & AGACCTCACGAAGCCAGAAA & 20 \\
\hline & Reverse & CTCTTCCTCCTCCTCCTCCT & 20 \\
\hline LOC103715998 & Forward & CACAGATTGTCGCACTCGTT & 20 \\
\hline & Reverse & GCCGGAATCAGGGTCATAGA & 20 \\
\hline LOC103719605 & Forward & CCAACGAAGGCTCTCAAAGG & 20 \\
\hline LOC103702656 & Reverse & TTGGAAGCCTCTGGTACAGG & 20 \\
\hline & Forward & GCATTCCATCCCATGACACC & 20 \\
\hline & Reverse & CCATCTTCTCTCCCTCGCAT & 20 \\
\hline & Forward & TTCGAGTTCTGTGGGCTCTT & 20 \\
\hline & Reverse & ACGGATAGCCTACTCAACGG & 20 \\
\hline & Forward & AGGCTGCGTTTGTATGTTCC & 20 \\
\hline & Reverse & TCACCCAAACAAGGCAAAGG & 20 \\
\hline
\end{tabular}

\subsection{Metabolite Analysis by LC-MS/MS}

Samples of leaves were analyzed through an HPLC-ESI-QTOF-MS/MS system (6520B, Agilent, Santa Clara, CA, USA), and fragmentation patterns were obtained in targeted MS2 mode. The data were processed using MassHunter Qualitative Analysis software (Agilent Technologies, Barcelona, Spain) [36]. Multiple reaction monitoring (MRM) was performed using an LC-ESI-Q TRAP-MS/MS (4000Q TRAP, ABI, Framingham, MA, USA) for the quantification of the metabolites. Data acquisition, curve calibration, peak integration, and calculations were performed with Analyst 1.6 software (AB SCIEX). The data processing and the analytical conditions were similar to those previously mentioned [36]. The qualitative and quantitative chromatographic parameters were the same: The HPLC column was a Shim-pack VP-ODS C18 (pore size $5.0 \mu \mathrm{m}$, length $2 \times 150 \mathrm{~mm}$ ); the column temperature was set at $40{ }^{\circ} \mathrm{C}$; the solvent system was water $(0.04 \%$ acetic acid added): acetonitrile $(0.04 \%$ acetic acid added). This method was used according to [36]. To quantify the amino acids and flavonoids, the area of each individual peak was calculated and compared to those of the standard curves, as reported previously $[34,36]$. 
Statistical analyses. Principal component analysis (PCA) was performed with R (www.r-project.org/ (accessed on 3 February 2021)) using the Pareto scaling method to obtain grouping information for nontargeted metabolomics data. Seventeen amino acids and 36 flavonoids were subjected to hierarchical clustering analysis via HemI (http:/ /hemi.biocuckoo.org/ (accessed on 3 February 2021)) to visualize the changes in metabolite profiles.

\section{Discussion}

In this study, HiSeq Illumina sequencing was used to characterize the transcriptome profiles of 60-day-old date palm seedlings in response to UV-B stress. Transcriptome analysis revealed a total of 44,853,794 clean reads, which were assembled into thousands of predicted genes. In total, 10,249 and 12,426 genes, whose expressions were upregulated and downregulated, were detected, compared to those in the control. A total of $96.34 \%$ of the identified unigenes were submitted to the NR protein database, as shown in Figure 1.

The current results revealed that the most affected cellular components involving the largest number of genes according to GO analysis were cell parts, organelles and membranes. This indicates that the plants try to protect their cells and organelles from UV$B$ exposure. In addition, the cellular process and metabolic process subcategories ranked first among the biological processes that help the plant produce antioxidants to protect biological process cycles against oxidative stress caused by UV-B radiation. For molecular function, the functions most affected by UV-B treatment were binding and catalytic activity. The balance between catalytic and metabolic processes determines the degree of resistance of plant cells to excess UV-B stress, which affects overall plant status. Our results agree with those of a previous report [34,37].

Gene expression analysis and functional annotation were performed on the genes overexpressed in response to excess UV-B. The genes whose expression was most upregulated included those encoding YLS9-like, germin-like protein 3-8 and P21-like. The products of these groups of genes are involved in ultraviolet radiation absorption, which is related to the plant defense system that activates the hypersensitive response against UV stress. Germin-like proteins (GLPs) can also increase the expression level of radiation resistancerelated genes, which enhance plant tolerance to different adverse environmental stresses, including excess radiation [38]. This hypersensitive action protects plant organelles against UV-B stress, which explains why the extremely high expression of these genes was significantly upregulated in date palm. Furthermore, proteins sensitive to proton rhizotoxicity 1-like and SNF1-related protein kinase regulatory subunit beta-1-like isoform X1 regulate many mechanisms related to specific stress tolerance mechanisms, particularly $\mathrm{H}^{+}$tolerance mechanisms. Furthermore, it was found that the harmful effects of UV-B radiation increased under combined stresses, especially at low $\mathrm{pH}$. This explains the high expression level of these two genes in leaf tissues (seven-fold higher than that in untreated plants). These two genes contribute to maximizing the plant defense mechanism against UV stress. In this study, UV-B radiation was found to influence multiple biological processes in plants either through various regulatory effects or via direct damage, and these results are in agreement with those in [39].

In addition, a group of genes were highly expressed as a result of UV-B stress, including pathogenesis-related (PR) protein 1-like, the transcriptional corepressor LEUNIG, glutathione-S-transferases (GSTs) and premnaspirodiene oxygenase-like. PR proteins play crucial roles in the plant defense system [40], and the transcriptional corepressor LEUNIG has a role in regulating genes that are involved in a variety of physiological processes, including disease resistance, response to DNA damage, and cell signaling. [41]. The detoxification of xenobiotics, limiting oxidative damage and other stress responses in plants have been associated with GSTs [42]. Premnaspirodiene oxygenase-like mainly participates in the synthesis of lignin, UV protectants, pigments, defense agents, hormones, fatty acids, and molecules for signaling [43]. Therefore, these genes increase tolerance to UV-B stress. As in the current study, a previously conducted study proved that these groups of genes 
have biological functions strongly related to responses to biotic and abiotic stresses, as well as UV light.

However, the current results found that the expression of the galactosyltransferase 2, flavanone 3-hydroxylase, fatty acyl-CoA reductase 4, caffeoyl shikimate esterase-like and protein LSD1 isoform X2 genes was downregulated compared to that of the control.

In this study, we analyzed the transcript levels of unigenes in the transcriptome data related to metabolic processes that were affected by UV-B radiation. We determined the nontarget metabolite contents and analyzed the metabolites that had significantly different levels compared with those of the control to explore the relations between UV-B radiation and metabolic processes. In this study, we identified many unigenes involved in different pathways in response to UV-B stress, and the shifts in primary and secondary metabolites were investigated [34].

The results showed that the unigenes related to the amino acid, phenylpropanoid and flavonoid biosynthesis pathways were affected by UV-B radiation. Therefore, the changes in metabolite contents were related to the difference in the unigenes transcript levels involved in metabolite pathway responses to UV-B stress. Amino acids are monomers that play major roles in forming proteins and are a major primary metabolite in plants. Additionally, amino acids can be catabolized into intermediates involved in many metabolic processes, such as the TCA cycle $[34,44,45]$. Amino acids play a wide variety of roles in protecting plants against different stresses and act as precursors of secondary metabolites related to plant defense against UV-B radiation [46]. It was found in previous studies that many amino acids, including glutamate, isoleucine, leucine, serine and proline, accumulate in plants affected by exposure to high levels of UV-B irradiation [34,47]. In addition, amino acid metabolism-related pathway activity was shown to increase or be induced, such as those involving phenylpropanoids and flavonoids (secondary metabolites), according to $[34,48]$. In this study, variations in amino acid (lysine, phenylalanine, tyrosine, glutamate, leucine, proline and alanine, etc.) contents in response to UV-B radiation were found in date palm leaves. Most of the amino acids increased significantly Compared with the control, under UV-B irradiation treatment, which revealed that date palm leaves tended to accumulate amino acids when exposed to UV-B radiation, as shown in Figure 3. Lysine increased compared with the control under UV-B irradiation treatment, and this result revealed that lysine responded to UV-B irradiation, which is consistent with a previous study, showing that lysine is involved in plant stress responses [34,44]. Lysine might be an intermediate of precursors of the TCA, as lysine is concerted into the energy-associated TCA cycle metabolite acetyl-CoA [49] in response to energy loss under conditions of stress [44]. According to these results, Under UV-B irradiation, lysine may play an important role in stress response. Glutamate levels decreased after $48 \mathrm{~h}$ of UV-B irradiation compared to the control levels, and decreased levels of glutamine play a major role in preserving the redox state by conversion into GABA and GSH in date palm leaves under UV-B irradiation, as shown in previous studies [34,50]. This result showed the accumulation of glutamine and GABA in response to UV-B stress, and GABA reduced oxidative stress caused by UV-B irradiation, which is consistent with the findings in previous studies [34]. In addition, some amino acids, including aspartate, lysine and glutamine, are closely associated with the formation of a regulatory metabolic pathway in date palm leaves in response to UV-B irradiation by forming antioxidant compounds. These results are in agreement with those of a previous study [34]. Furthermore, some amino acids contributed to the biosynthesis of secondary metabolites, such as flavonoids, under UV-B irradiation [34,51]. Phenylalanine and tyrosine participate as intermediates in the phenylpropanoid pathway. This leads to flavonoid biosynthesis in plants under UV-B irradiation. [52]. These results revealed that phenylpropanoids are involved in the biosynthesis of flavonoids, which help to protect date palm against UV-B stress. Furthermore, flavonoids accumulate in plants under different stresses, including UV-B stress, and function as inhibitors of ROS generation and as ROS scavengers $[20,21,53,54]$. In this study, the contents of many flavonoid under UV-B irradiation increased compared with those of the control, as shown in Figure 4. 
In the current study, transcription factors were identified as regulatory proteins that are involved in regulating the expression of other genes that participate in the UV-B stress response, including F-box, MYB, WRKY, chaperone, NRT1/PTR family member, ABC transporter, GTP-binding, NAC, bHLH, kinase and calmodulin proteins. These transcription factors are expressed in response to ultraviolet absorption. They are triggered by various signal transduction pathways and can bind to cis-acting elements directly or indirectly to modulate the transcription efficiency of target genes. Therefore, these proteins can act as key regulators of crop genetic improvement.

Furthermore, members of the MYB transcription family were found to have a positive effect in synthesizing phenylpropanoid compounds to absorb UV-B radiation and that are involved in regulating the balance for the production and accumulation of sunscreen-type compounds for radiation tolerance (Jin, H. et al., 2000) [8]. These transcription factors enhance tolerance to UV-B radiation and pathogen attack through enforcing the walls of plant cells to increase the accumulation of wax and deposition of lignin [55].

Chloroplast genes are related to light absorption and have an important role during exposure to UV-B stress. In the present study, the chloroplast-related genes whose expressions were most upregulated included zeaxanthin epoxidase, chaperone protein dnaJ-11 and protein kinase, presenting expression levels three times higher than those of the control. Zeaxanthin epoxidase is related to carotenoids and has an essential function in the photosynthetic machinery. In addition to its important role in light harvesting, this enzyme also plays an important role in de-epoxidation via the inhibition of photosynthetic activity under UV-B stress [56]. In the present experiment, protein kinase was found to be hyperactivated in response to UV-B, which is photo-repair deficiency, indicating that UV-damaged DNA is a cause for protein kinase signaling [57].

It was found that there was a total of 12 genes expressed in date palm leaf tissues, with levels more than two-fold greater than those in the control. These genes are involved in increasing plant defense against conditions of environmental stress, such as high light, $\mathrm{H}_{2} \mathrm{O}_{2}$, methyl viologen and copper sulfate. Furthermore, copper chaperones for superoxide dismutase play a major role in protecting plants against oxidative stress caused by UV-B exposure [58]. Cyanidin 3-O-rutinoside 5-O-glucosyltransferase-like is responsible for accumulating cyanidin 3-O-rutinoside in large amounts under UV-B stress. Systematically, it has a major role in effective protection against UV stress [59]. In agreement with the current results, it was found that the most pronounced function of these genes is reducing oxidative damage and UV light penetration into the layers of photosynthetic cells; moreover, it increases DNA repair and antioxidative defense [60].

In this study, chloroplast genes whose expressions were downregulated included thioredoxin M-type protein, early light-induced protein 1, magnesium-chelatase subunit ChlH, CURVATURE THYLAKOID 1B, anthranilate synthase beta subunit 2, photosystem II $22 \mathrm{kDa}$ protein, early light-induced protein, photosystem II $10 \mathrm{kDa}$ polypeptide, phosphoglycolate phosphatase $1 \mathrm{~B}$ and a glutamine synthetase leaf isozyme. The downregulated expression of thioredoxin M-type due to UV-B stress was found to reduce the stability of the photosystem II complex and decrease reactive oxygen species levels. It also increases oxidative activity, which can affect plant mechanisms, according to [61]. Early light-induced protein 1 is involved in the regulation of the redox state of the cell and plays an important role in protecting the photosystem under photo-oxidative stress. In this study, the expression of early light-induced protein 1 was downregulated in response to UV-B stress. The downregulated expression of these genes negatively affects the function of protecting the photosystem under photooxidative stress [62]. Depending on the abovementioned findings, it can be said that, under UV-B stress, the chloroplast genes whose expression was downregulated caused the misregulation of the redox state of the cell and protection of the photosystem, which negatively affected plants.

Photosystem mechanisms involve three processes: photosystem II, photosystem I and photosynthetic electron transport. The effects of UV-B stress on Photosystem II induced the downregulated expression of many genes, including Psbo, Psbp, PsbR, PsbQ, PsbS, Psb27 
and Psb28. In addition, the water-splitting and oxygen-evolving reactions catalyzed during the photosynthetic process by Photosystem II were highly affected. UV-B radiation damage affects the catalytic Mn cluster involved in water oxidation, which is most likely sensitive to the UV absorption of $\mathrm{MN}$ (III) and $\mathrm{MN}(\mathrm{IV})$ ion ligation by organic residues, according to [63]. Furthermore, Photosystem I was also affected by UV-B, which downregulated the expression of several genes, including PsaD, PsaG, PsaK, PsaL, PsaN and PsaO. PSI and PSII can physically dissociate from the major mobile light-harvesting chlorophyll $\mathrm{a} / \mathrm{b}$ complex II (LHCII), according to [64]. The photosynthetic electron transport process was associated with genes whose expressions were downregulated, including petE (PC), Fd (petF) and FNR (PetH). Furthermore, the expression of most photosynthesis-related genes was downregulated in response to UV-B stress. In the current study, UV-B significantly reduced the activity of photosystem I, photosystem II and the whole chain. These results are in agreement with those of [65]. In addition, the expressions of most oxidative phosphorylation related genes were up-regulated, i.e., cytochrome oxidase (COX10 and COX6B), was upregulated. In this study, it was found that UV-B radiation mediated oxidative stress as a protective mechanism by producing ROS and stimulating the activity of antioxidant enzymes, which was also previously reported by [66].

The results of qRT-PCR corresponded with the expression patterns of unigenes detected in the RNA-seq data. The upregulated expression of these genes suggests that various pathways in date palm leaves were caused by UV-B irradiation. We analyzed the transcriptome data to investigate the differentially expressed genes related to UV-B stress and compared the genes whose expression was upregulated and downregulated, which were shown in our results (transcription factor-related genes, chloroplast-related genes and photosystem-related genes) under UV-B stress. Furthermore, comprehensive metabolic profiling was performed to explore the variations in primary and secondary metabolites in date palm leaves under UV-B irradiation. We identified/annotated 50 metabolites in date palm leaves under UV-B irradiation by using an LC-MS/MS system. The altered levels of various metabolites, mainly those involved in the metabolism of amino acids and pathways of flavonoid biosynthesis, together with the variation in associated unigenes in the transcript stages, shed light on the potential interactions of amino acid metabolism with plant energy activities and secondary metabolism in date palm leaves in response to UV-B irradiation. Our findings enhance the understanding of the metabolic control of date palm leaves in response to UV-B irradiation and pave the way for further dissection under stress conditions of metabolic pathways in date palm.

Author Contributions: Conceptualization, M.M. and E.N.; methodology, H.A.; software, M.M.; validation, M.M., Y.L. and J.L.; formal analysis, M.M.; investigation, J.L.; resources, H.A.; data curation, M.M.; writing — original draft preparation, M.M.; writing—review and editing, Y.L.; visualization, H.A.; supervision, J.L.; project administration, J.L.; funding acquisition, J.L. All authors have read and agreed to the published version of the manuscript.

Funding: This research was funded by the National Science Fund for Distinguished Young Scholars (No. 31625021).

Institutional Review Board Statement: Not applicable.

Informed Consent Statement: Not applicable.

Data Availability Statement: RNA sequence data that support the findings of this study have been deposited under SRA BioProject accession number PRJNA622884.

Acknowledgments: The authors would like to thank Maher Agwa, father of Mohamed Maher, for his brought the motivation for his scientific career.

Conflicts of Interest: The authors declare no competing interests. 


\section{References}

1. Food and Agriculture Organization of the United Nations. Worldwide Dates Production Statistics; Food and Agriculture Organization of the United Nations: Rome, Italy, 2006.

2. Chao, C.T.; Krueger, R.R. The date palm (Phoenix dactylifera L.): Overview of biology, uses, and cultivation. HortScience 2007, 42, 1077-1082. [CrossRef]

3. Al-Harrasi, A.; Rehman, N.U.; Hussain, J.; Khan, A.L.; Al-Rawahi, A.; Gilani, S.A.; Al-Broumi, M.; Ali, L. Nutritional assessment and antioxidant analysis of 22 date palm (Phoenix dactylifera) varieties growing in Sultanate of Oman. Asian Pac. J. Trop. Med. 2014, 7, S591-S598. [CrossRef]

4. Hazzouri, K.M.; Flowers, J.M.; Visser, H.J.; Khierallah, H.S.; Rosas, U.; Pham, G.M.; Meyer, R.S.; Johansen, C.K.; Fresquez, Z.A.; Masmoudi, K. Whole genome re-sequencing of date palms yields insights into diversification of a fruit tree crop. Nat. Commun. 2015, 6, 1-11. [CrossRef] [PubMed]

5. Soliman, S.; Al-Obeed, R.; Harhash, M. Effects of bunch thinning on yield and fruit quality of khalas date palm cultivar. World J. Agric. Sci. 2011, 7, 42-46.

6. Gao, W.; Lv, D.; Yu, C.; Qin, S.; Du, G.; Zhao, D. Study on microorganism population structure in microenvironment of bagged apple fruit. J. Fruit Sci. 2007, 24, 830-832.

7. Liu, J.; Li, B.; Zhang, L.; Luan, D.; Li, Y.; Lei, Y. The effect of bagging on the quality and pesticide residual of 'Red Fuji'apple. J. Northwest Sci.-Tech. Univ. Agric. For. 2003, 10, 16-18.

8. Andrady, A.; Aucamp, P.J.; Bais, A.F.; Ballare, C.L.; Björn, L.; Bornman, J.F.; Caldwell, M.; Cullen, A.P.; Erickson, D.J.; Häder, D. Environmental effects of ozone depletion and its interactions with climate change: Progress report, 2009. Photochem. Photobiol. Sci. Off. J. Eur. Photochem. Assoc. Eur. Soc. Photobiol. 2010, 9, 275-294.

9. Jansen, M.A.; Gaba, V.; Greenberg, B.M. Higher plants and UV-B radiation: Balancing damage, repair and acclimation. Trends Plant Sci. 1998, 3, 131-135. [CrossRef]

10. Teramura, A.H.; Sullivan, J.H. Effects of UV-B radiation on photosynthesis and growth of terrestrial plants. Photosynth. Res. 1994, 39, 463-473. [CrossRef]

11. Jassim, S.A.; Limoges, R.G. Impact of external forces on cyanophage-host interactions in aquatic ecosystems. World J. Microbiol. Biotechnol. 2013, 29, 1751-1762. [CrossRef] [PubMed]

12. Miyamura, Y.; Coelho, S.G.; Schlenz, K.; Batzer, J.; Smuda, C.; Choi, W.; Brenner, M.; Passeron, T.; Zhang, G.; Kolbe, L. The deceptive nature of UVA tanning versus the modest protective effects of UVB tanning on human skin. Pigment Cell Melanoma Res. 2011, 24, 136-147. [CrossRef] [PubMed]

13. Kusano, M.; Tohge, T.; Fukushima, A.; Kobayashi, M.; Hayashi, N.; Otsuki, H.; Kondou, Y.; Goto, H.; Kawashima, M.; Matsuda, F Metabolomics reveals comprehensive reprogramming involving two independent metabolic responses of Arabidopsis to UV-B light. Plant J. 2011, 67, 354-369. [CrossRef]

14. Kim, S.; Yun, E.J.; Hossain, M.A.; Lee, H.; Kim, K.H. Global profiling of ultraviolet-induced metabolic disruption in Melissa officinalis by using gas chromatography-mass spectrometry. Anal. Bioanal. Chem. 2012, 404, 553-562. [CrossRef] [PubMed]

15. Landry, L.G.; Chapple, C.C.; Last, R.L. Arabidopsis mutants lacking phenolic sunscreens exhibit enhanced ultraviolet-B injury and oxidative damage. Plant Physiol. 1995, 109, 1159-1166. [CrossRef] [PubMed]

16. Rao, M.V.; Paliyath, G.; Ormrod, D.P. Ultraviolet-B-and ozone-induced biochemical changes in antioxidant enzymes of Arabidopsis thaliana. Plant Physiol. 1996, 110, 125-136. [CrossRef]

17. Czégény, G.; Mátai, A.; Hideg, É. UV-B effects on leaves-Oxidative stress and acclimation in controlled environments. Plant Sci. 2016, 248, 57-63. [CrossRef]

18. Zhu, W.; Yang, B.; Komatsu, S.; Lu, X.; Li, X.; Tian, J. Binary stress induces an increase in indole alkaloid biosynthesis in Catharanthus roseus. Front. Plant Sci. 2015, 6, 582. [CrossRef]

19. Harborne, J.B.; Williams, C.A. Advances in flavonoid research since 1992. Phytochemistry 2000, 55, 481-504. [CrossRef]

20. Agati, G.; Stefano, G.; Biricolti, S.; Tattini, M. Mesophyll distribution of 'antioxidant'flavonoid glycosides in Ligustrum vulgare leaves under contrasting sunlight irradiance. Ann. Bot. 2009, 104, 853-861. [CrossRef]

21. Agati, G.; Biricolti, S.; Guidi, L.; Ferrini, F.; Fini, A.; Tattini, M. The biosynthesis of flavonoids is enhanced similarly by UV radiation and root zone salinity in L. vulgare leaves. J. Plant Physiol. 2011, 168, 204-212. [CrossRef]

22. Al-Mssallem, I.S.; Hu, S.; Zhang, X.; Lin, Q.; Liu, W.; Tan, J.; Yu, X.; Liu, J.; Pan, L.; Zhang, T. Genome sequence of the date palm Phoenix dactylifera L. Nat. Commun. 2013, 4, 2274. [CrossRef]

23. Al-Dous, E.K.; George, B.; Al-Mahmoud, M.E.; Al-Jaber, M.Y.; Wang, H.; Salameh, Y.M.; Al-Azwani, E.K.; Chaluvadi, S.; Pontaroli, A.C.; DeBarry, J. De novo genome sequencing and comparative genomics of date palm (Phoenix dactylifera). Nat. Biotechnol. 2011, 29, 521. [CrossRef]

24. Mathew, L.S.; Spannagl, M.; Al-Malki, A.; George, B.; Torres, M.F.; Al-Dous, E.K.; Al-Azwani, E.K.; Hussein, E.; Mathew, S.; Mayer, K.F. A first genetic map of date palm (Phoenix dactylifera) reveals long-range genome structure conservation in the palms. BMC Genom. 2014, 15, 1-10. [CrossRef]

25. Zhang, G.; Pan, L.; Yin, Y.; Liu, W.; Huang, D.; Zhang, T.; Wang, L.; Xin, C.; Lin, Q.; Sun, G. Large-scale collection and annotation of gene models for date palm (Phoenix dactylifera, L.). Plant Mol. Biol. 2012, 79, 521-536. [CrossRef] [PubMed]

26. Zhang, L.; Zhao, G.; Xia, C.; Jia, J.; Liu, X.; Kong, X. A wheat R2R3-MYB gene, TaMYB30-B, improves drought stress tolerance in transgenic Arabidopsis. J. Exp. Bot. 2012, 63, 5873-5885. [CrossRef] [PubMed] 
27. Bourgis, F.; Kilaru, A.; Cao, X.; Ngando-Ebongue, G.-F.; Drira, N.; Ohlrogge, J.B.; Arondel, V. Comparative transcriptome and metabolite analysis of oil palm and date palm mesocarp that differ dramatically in carbon partitioning. Proc. Natl. Acad. Sci. USA 2011, 108, 12527-12532. [CrossRef] [PubMed]

28. Zhang, F.; Guo, H.; Huang, J.; Yang, C.; Li, Y.; Wang, X.; Qu, L.; Liu, X.; Luo, J. A UV-B-responsive glycosyltransferase, OsUGT706C2, modulates flavonoid metabolism in rice. Sci. China Life Sci. 2020, 63, 1037-1052. [CrossRef]

29. Haas, B.J.; Papanicolaou, A.; Yassour, M.; Grabherr, M.; Blood, P.D.; Bowden, J.; Couger, M.B.; Eccles, D.; Li, B.; Lieber, M.; et al. De novo transcript sequence reconstruction from RNA-seq using the Trinity platform for reference generation and analysis. Nat. Protoc. 2013, 8, 1494-1512. [CrossRef] [PubMed]

30. Götz, S.; García-Gómez, J.M.; Terol, J.; Williams, T.D.; Nagaraj, S.H.; Nueda, M.J.; Robles, M.; Talón, M.; Dopazo, J.; Conesa, A. High-throughput functional annotation and data mining with the Blast2GO suite. Nucleic Acids Res. 2008, 36, 3420-3435. [CrossRef]

31. Young, M.D.; Wakefield, M.J.; Smyth, G.K.; Oshlack, A. Gene ontology analysis for RNA-seq: Accounting for selection bias. Genome Biol. 2010, 11, R14. [CrossRef] [PubMed]

32. Kanehisa, M.; Araki, M.; Goto, S.; Hattori, M.; Hirakawa, M.; Itoh, M.; Katayama, T.; Kawashima, S.; Okuda, S.; Tokimatsu, T. KEGG for linking genomes to life and the environment. Nucleic Acids Res. 2007, 36, D480-D484. [CrossRef] [PubMed]

33. Arisha, M.H.; Ahmad, M.Q.; Tang, W.; Liu, Y.; Yan, H.; Kou, M.; Wang, X.; Zhang, Y.; Li, Q. RNA-sequencing analysis revealed genes associated drought stress responses of different durations in hexaploid sweet potato. Sci. Rep. 2020, 10, 1-17. [CrossRef]

34. Zhang, X.; Ding, X.; Ji, Y.; Wang, S.; Chen, Y.; Luo, J.; Shen, Y.; Peng, L. Measurement of metabolite variations and analysis of related gene expression in Chinese liquorice (Glycyrrhiza uralensis) plants under UV-B irradiation. Sci. Rep. 2018, 8, 1-17. [CrossRef] [PubMed]

35. Livak, K.J.; Schmittgen, T.D. Analysis of relative gene expression data using real-time quantitative PCR and the $2-\Delta \Delta C T$ method. Methods 2001, 25, 402-408. [CrossRef] [PubMed]

36. Wang, S.; Tu, H.; Wan, J.; Chen, W.; Liu, X.; Luo, J.; Xu, J.; Zhang, H. Spatio-temporal distribution and natural variation of metabolites in citrus fruits. Food Chem. 2016, 199, 8-17. [CrossRef]

37. Aioub, A.A.; Zuo, Y.; Li, Y.; Qie, X.; Zhang, X.; Essmat, N.; Wu, W.; Hu, Z. Transcriptome analysis of Plantago major as a phytoremediator to identify some genes related to cypermethrin detoxification. Environ. Sci. Pollut. Res. 2020, 28, 5101-5115. [CrossRef]

38. Banerjee, J.; Das, N.; Dey, P.; Maiti, M.K. Transgenically expressed rice germin-like protein1 in tobacco causes hyper-accumulation of $\mathrm{H} 2 \mathrm{O} 2$ and reinforcement of the cell wall components. Biochem. Biophys. Res. Commun. 2010, 402, 637-643. [CrossRef]

39. Zlatev, Z.S.; Lidon, F.J.; Kaimakanova, M. Plant physiological responses to UV-B radiation. Emir. J. Food Agric. 2012, 24 , 481-501. [CrossRef]

40. Jiang, L.; Wu, J.; Fan, S.; Li, W.; Dong, L.; Cheng, Q.; Xu, P.; Zhang, S. Isolation and characterization of a novel pathogenesis-related protein gene (GmPRP) with induced expression in soybean (Glycine max) during infection with Phytophthora sojae. PLoS ONE 2015, 10, e0129932. [CrossRef] [PubMed]

41. Gonzalez, D.; Bowen, A.J.; Carroll, T.S.; Conlan, R.S. The transcription corepressor LEUNIG interacts with the histone deacetylase HDA19 and mediator components MED14 (SWP) and CDK8 (HEN3) to repress transcription. Mol. Cell. Biol. 2007, 27, 5306-5315. [CrossRef]

42. Gong, H.; Jiao, Y.; Hu, W.-W.; Pua, E.-C. Expression of glutathione-S-transferase and its role in plant growth and development in vivo and shoot morphogenesis in vitro. Plant Mol. Biol. 2005, 57, 53-66. [CrossRef]

43. Niño, M.C.; Song, J.-Y.; Nogoy, F.M.; Kim, M.-S.; Jung, Y.J.; Kang, K.-K.; Nou, I.; Cho, Y.-G. Overexpression of rice premnaspirodiene oxygenase reduces the infection rate of Xanthomonas oryzae pv. oryzae. J. Plant Biotechnol. 2016, 43, 422-431. [CrossRef]

44. Galili, G. The aspartate-family pathway of plants: Linking production of essential amino acids with energy and stress regulation. Plant Signal. Behav. 2011, 6, 192-195. [CrossRef]

45. Zhu, X.; Galili, G. Increased lysine synthesis coupled with a knockout of its catabolism synergistically boosts lysine content and also transregulates the metabolism of other amino acids in Arabidopsis seeds. Plant Cell 2003, 15, 845-853. [CrossRef]

46. Stepansky, A.; Galili, G. Synthesis of the Arabidopsis bifunctional lysine-ketoglutarate reductase/saccharopine dehydrogenase enzyme of lysine catabolism is concertedly regulated by metabolic and stress-associated signals. Plant Physiol. 2003, 133, 1407-1415. [CrossRef]

47. Aksakal, O.; Tabay, D.; Esringu, A.; Aksakal, F.I.; Esim, N. Effect of proline on biochemical and molecular mechanisms in lettuce (Lactuca sativa L.) exposed to UV-B radiation. Photochem. Photobiol. Sci. 2017, 16, 246-254. [CrossRef]

48. Yang, B.; Wang, X.; Gao, C.; Chen, M.; Guan, Q.; Tian, J.; Komatsu, S. Proteomic and metabolomic analyses of leaf from Clematis terniflora DC. exposed to high-Level ultraviolet-B irradiation with dark treatment. J. Proteome Res. 2016, 15, 2643-2657. [CrossRef] [PubMed]

49. Arruda, P.; Kemper, E.L.; Papes, F.; Leite, A. Regulation of lysine catabolism in higher plants. Trends Plant Sci. 2000, 5, 324-330. [CrossRef]

50. Noctor, G.; Foyer, C.H. Ascorbate and glutathione: Keeping active oxygen under control. Annu. Rev. Plant Biol. 1998, 49, 249-279. [CrossRef] 
51. Häusler, R.E.; Ludewig, F.; Krueger, S. Amino acids-A life between metabolism and signaling. Plant Sci. 2014, $229,225-237$. [CrossRef]

52. Buer, C.S.; Imin, N.; Djordjevic, M.A. Flavonoids: New roles for old molecules. J. Integr. Plant Biol. 2010, 52, 98-111. [CrossRef]

53. Ryan, K.G.; Markham, K.R.; Bloor, S.J.; Bradley, J.M.; Mitchell, K.A.; Jordan, B.R. UVB radiation induced increase in quercetin: Kaempferol ratio in wild-type and transgenic lines of Petunia. Photochem. Photobiol. 1998, 68, 323-330. [CrossRef]

54. Tattini, M.; Galardi, C.; Pinelli, P.; Massai, R.; Remorini, D.; Agati, G. Differential accumulation of flavonoids and hydroxycinnamates in leaves of Ligustrum vulgare under excess light and drought stress. New Phytol. 2004, 163, 547-561. [CrossRef]

55. Wang, H.; Hao, J.; Chen, X.; Hao, Z.; Wang, X.; Lou, Y.; Peng, Y.; Guo, Z. Overexpression of rice WRKY89 enhances ultraviolet B tolerance and disease resistance in rice plants. Plant Mol. Biol. 2007, 65, 799-815. [CrossRef] [PubMed]

56. Guidi, L.; Brunetti, C.; Fini, A.; Agati, G.; Ferrini, F.; Gori, A.; Tattini, M. UV radiation promotes flavonoid biosynthesis, while negatively affecting the biosynthesis and the de-epoxidation of xanthophylls: Consequence for photoprotection? Environ. Exp. Bot. 2016, 127, 14-25. [CrossRef]

57. Gonzalez Besteiro, M.A.; Ulm, R. ATR and MKP 1 play distinct roles in response to UV-B stress in Arabidopsis. Plant J. 2013, 73, 1034-1043. [CrossRef]

58. Kliebenstein, D.J.; Monde, R.-A.; Last, R.L. Superoxide dismutase in Arabidopsis: An eclectic enzyme family with disparate regulation and protein localization. Plant Physiol. 1998, 118, 637-650. [CrossRef]

59. Eguchi, K.; Sato, T. Differences in the ratios of cyanidin-3-O-glucoside and cyanidin-3-O-rutinocide to total anthocyanin under UV and non-UV conditions in Tartary Buckwheat (Fagopyrum tataricum Garten). Plant Prod. Sci. 2009, 12, 150-155. [CrossRef]

60. Escobar-Bravo, R.; Klinkhamer, P.G.; Leiss, K.A. Interactive effects of UV-B light with abiotic factors on plant growth and chemistry, and their consequences for defense against arthropod herbivores. Front. Plant Sci. 2017, 8, 278. [CrossRef]

61. Wang, P.; Liu, J.; Liu, B.; Feng, D.; Da, Q.; Shu, S.; Su, J.; Zhang, Y.; Wang, J.; Wang, H.-B. Evidence for a role of chloroplastic m-type thioredoxins in the biogenesis of photosystem II in Arabidopsis. Plant Physiol. 2013, 163, 1710-1728. [CrossRef]

62. Lee, J.W.; Lee, S.H.; Han, J.W.; Kim, G.H. Early light-inducible protein (ELIP) can enhance resistance to cold-induced photooxidative stress in Chlamydomonas reinhardtii. Front. Physiol. 2020, 11, 1083. [CrossRef]

63. Ghetti, F.; Checcucci, G.; Bornman, J.F. Environmental uv radiation: Impact on ecosystems and human health and predictive models. In Proceedings of the Nato Advanced Study Institute on Environmental Uv Radiation: Impact on Ecosystems and Human Health and Predictive Models, Pisa, Italy, 3 June 2001.

64. Ivanov, A.G.; Velitchkova, M.Y.; Allakhverdiev, S.I.; Huner, N.P. Heat stress-induced effects of photosystem I: An overview of structural and functional responses. Photosynth. Res. 2017, 133, 17-30. [CrossRef]

65. Prasad, S.; Dwivedi, R.; Zeeshan, M. Growth, photosynthetic electron transport, and antioxidant responses of young soybean seedlings to simultaneous exposure of nickel and UV-B stress. Photosynthetica 2005, 43, 177-185. [CrossRef]

66. Kim, B.-M.; Rhee, J.-S.; Lee, K.-W.; Kim, M.-J.; Shin, K.-H.; Lee, S.-J.; Lee, Y.-M.; Lee, J.-S. UV-B radiation-induced oxidative stress and p38 signaling pathway involvement in the benthic copepod Tigriopus japonicus. Comp. Biochem. Physiol. Part C Toxicol. Pharmacol. 2015, 167, 15-23. [CrossRef] 